UCRL-ID-130228

\title{
Accelerated Cleanup Risk Reduction
}

\author{
R. B. Knapp, R. M. Aines, R. G. Blake, A. B. Copeland, \\ K. J. Jackson, R. L. Newmark, A. F. B. Tompson
}

February, 1998

This is an informal report intended primarily for internal or limited external distribution. The opinions and conclusions stated are those of the author and may or may not be those of the Laboratory.

Work performed under the auspices of the U.S. Department of Energy by the Lawrence Livermore National Laboratory under Contract W-7405-Eng-48. 


\section{DISCLAIMER}

This document was prepared as an account of work sponsored by an agency of the United States Government. Neither the United States Government nor the University of California nor any of their employees, makes any warranty, express or implied, or assumes any legal liability or responsibility for the accuracy, completeness, or usefulness of any information, apparatus, product, or process disclosed, or represents that its use would not infringe privately owned rights. Reference herein to any specific commercial product, process, or service by trade name, trademark, manufacturer, or otherwise, does not necessarily constitute or imply its endorsement, recommendation, or favoring by the United States Government or the University of California. The views and opinions of authors expressed herein do not necessarily state or reflect those of the United States Government or the University of California, and shall not be used for advertising or product endorsement purposes.

This report has been reproduced directly from the best available copy.

Available to DOE and DOE contractors from the Office of Scientific and Technical Information

P.O. Box 62, Oak Ridge, TN 37831

Prices available from (615) 576-8401, FTS 626-8401

Available to the public from the

National Technical Information Service

U.S. Department of Commerce

5285 Port Royal Rd.,

Springfield, VA 22161 


\section{Accelerated Cleanup Risk Reduction}

An approach for rapid site closure using new technologies to eliminate contaminant plume source regions.

\section{$\underline{\text { Research Team }}$}

Knapp, R.B., R.M Aines, R.G. Blake, A.B. Copeland, K.J. Jackson, R.L. Newmark, and A.F.B. Tompson

\section{Lawrence Livermore National Laboratory}

February, 1998 


\section{Table of Contents}

Abstract 1

Introduction 2

LLNL Main Site $\quad 2$

Plume Source Regions 3

System of Technologies 5

Hydrous Pyrolysis/Oxidation 5

In Situ Microbial Filters $\quad 5$

Process Monitoring 5

Contaminant Targeting 6

Comprehensive Team Approach 7

Hydrous Pyrolysis/Oxidation $\quad 10$

Introduction $\quad 10$

Chemical Basis for In situ Destruction $\quad 10$

Background 10

Experimental approach $\quad 11$

Theoretical basis $\quad 12$

Results 13

Oxidation via coupled $\mathrm{MnO}_{2}$ reduction $\quad 14$

Thermodynamic data determinations $\quad 15$

Field Implementation $\quad 16$

Process control 19

Long-term effects 20

Vadose zone effects 20

Visalia Field Test $\quad 20$

Background 21

Field analysis 23

In Situ Microbial Filters 26

Concept 26

A Proof-of-Concept Field Experiment 26

LLNL Site Approach $\quad 27$

Site suitability $\quad 27$

Biofilter design 28

Coupling with hydrous pyrolysis 29

Process Monitoring $\quad 30$

Introduction $\quad 30$

Issues and Implementation $\quad 30$

Steam injection $\quad 30$

Microbial filter $\quad 31$

Contaminant Targeting 33

References $\quad 34$ 


\begin{abstract}
There is no proven technology for remediating contaminant plume source regions in a heterogeneous subsurface. This project is an interdisciplinary effort to develop the requisite new technologies so that will be rapidly accepted by the remediation community. Our technology focus is hydrous pyrolysis/oxidation (HPO) which is a novel in situ thermal technique. We have expanded this core technology to leverage the action of steam injection and place an in situ microbial filter downstream to intercept and destroy the accelerated movement of contaminated groundwater.

Most contaminant plume source regions, including the chlorinated solvent plume at LLNL, are in subsurface media characterized by a wide range in hydraulic conductivity. At LLNL, the main conduits for contaminant transport are buried stream channels composed of gravels and sands; these have a hydraulic conductivity in the range of $10^{-6}$ to $10^{-2} \mathrm{~cm} / \mathrm{s}$. Clay and silt units with a hydraulic conductivity of $10^{-8}$ to $10^{-6} \mathrm{~cm} / \mathrm{s}$ bound these buried channels; these are barriers to groundwater movement and contain the highest contaminant concentrations in the source region. New remediation technologies are required because the current ones preferentially access the high conductivity units.

HPO is an innovative process for the in situ destruction of contaminants in the entire subsurface. It operates by the injection of steam. We have demonstrated in laboratory experiments that many contaminants rapidly oxidize to harmless compounds at temperatures easily achieved by injecting steam, provided sufficient dissolved oxygen is present. One important challenge in a heterogeneous source region is getting heat, contaminants, and an oxidizing agent in the same place at the same time.

We have used the NUFT computer program to simulate the cyclic injection of steam into a contaminated aquifer for design of a field demonstration. We used an 8 hour, steam/oxygen injection cycle followed by a 56 hour relaxation period in which the well was "capped". Our results show the formation of an inclined gas phase during injection and a fast collapse of the steam zone within an hour of terminating steam injection. The majority of destruction occurs during the collapse phase, when contaminant laden water is drawn back towards the well. Little to no noncondensible gasses are created in this process, removing any possibility of sparging processes interfering with contaminant destruction. Our models suggest that the thermal region should bc as hot and as large as possible.

To have HPO accepted, we need to demonstrate the in situ destruction of contaminants. This requires the ability to inexpensively sample at depth and under high temperatures. We proved the ability to emplace monitoring points at depths exceeding 150 feet in highly heterogeneous soils by use of cone penetrometry. In addition, an extractive system has been developed for sampling fluids and measuring their chemistry under the range of extreme conditions expected.

We conducted a collaborative field test of HPO at a Superfund site in southern California where the contaminant is mainly creosote and pentachlorophenol. Field results confirm the destruction of contaminants by HPO, validate our field design from simulations, demonstrate that accurate field measurements of the critical fluid parameters can be obtained using existing monitoring wells (and minimal capital cost) and yield reliable cost estimates for future commercial application.

We also tested the in situ microbial filter technology as a means to intercept and destroy the accelerated flow of contaminants caused by the injection of steam. A series of laboratory and field tests revealed that the selected bacterial species effectively degrades trichloroethene in LLNL groundwater and under LLNL site conditions. In addition, it was demonstrated that the bacteria effectively attach to the LLNL subsurface media. An in-well treatability study indicated that the bacteria initially degrade $>99 \%$ of the contaminant, to concentrations less than regulatory limits. The duration of this in situ performance is not currently known, but should be consistent with previous field tests.
\end{abstract}




\section{Introduction}

There is a great need for new approaches for rapid contaminant plume cleanup and site closure at competitive costs. This need is perceived most by property owners who are prevented from selling or developing due to the lengthy duration of pump-and-treat operations, who have unacceptable maintenance and operation costs, or who experienced continuing negative community relations due to lack of closure. These include both private and government concerns.

This project attacks this problem by using new technologies to rapidly eliminate the source region for contaminant plumes while preventing further expansion of either the distal plume or the source region itself. The LLNL Main site could serve as both a test bed for technology development and as a location for one of the first, full-scale accelerated site closures. New technologies are required because pump-and-treat has been proven ineffective in the rapid elimination of appreciable volumes of contaminated groundwater. In the following paragraphs, we will describe the LLNL Main site, our strategy for rapid closure, and the technologies we have developed.

\section{LLNL Main Site}

VOC contaminated groundwater is the primary CERCLA problem at the LLNL site. Their presence in groundwater both within and outside the site boundaries resulted in the LLNL Main site being placed in EPA's CERCLA National Priorities List. Contaminant concentrations above MCLs occur under about $85 \%$ of the site and account for approximately $100 \mathrm{M}$ gallons of contaminated groundwater (Fig. 1). A high concentration contaminant plume source region is located in the eastern portions of the site. It accounts for only about $10 \%$ of the contaminated fluid volume but approximately $90 \%$ of the contaminant mass. Part of the distal, more dilute and mobile contaminant plume has migrated off-site to the west. Total VOC concentrations as high as $30 \mathrm{ppm}$

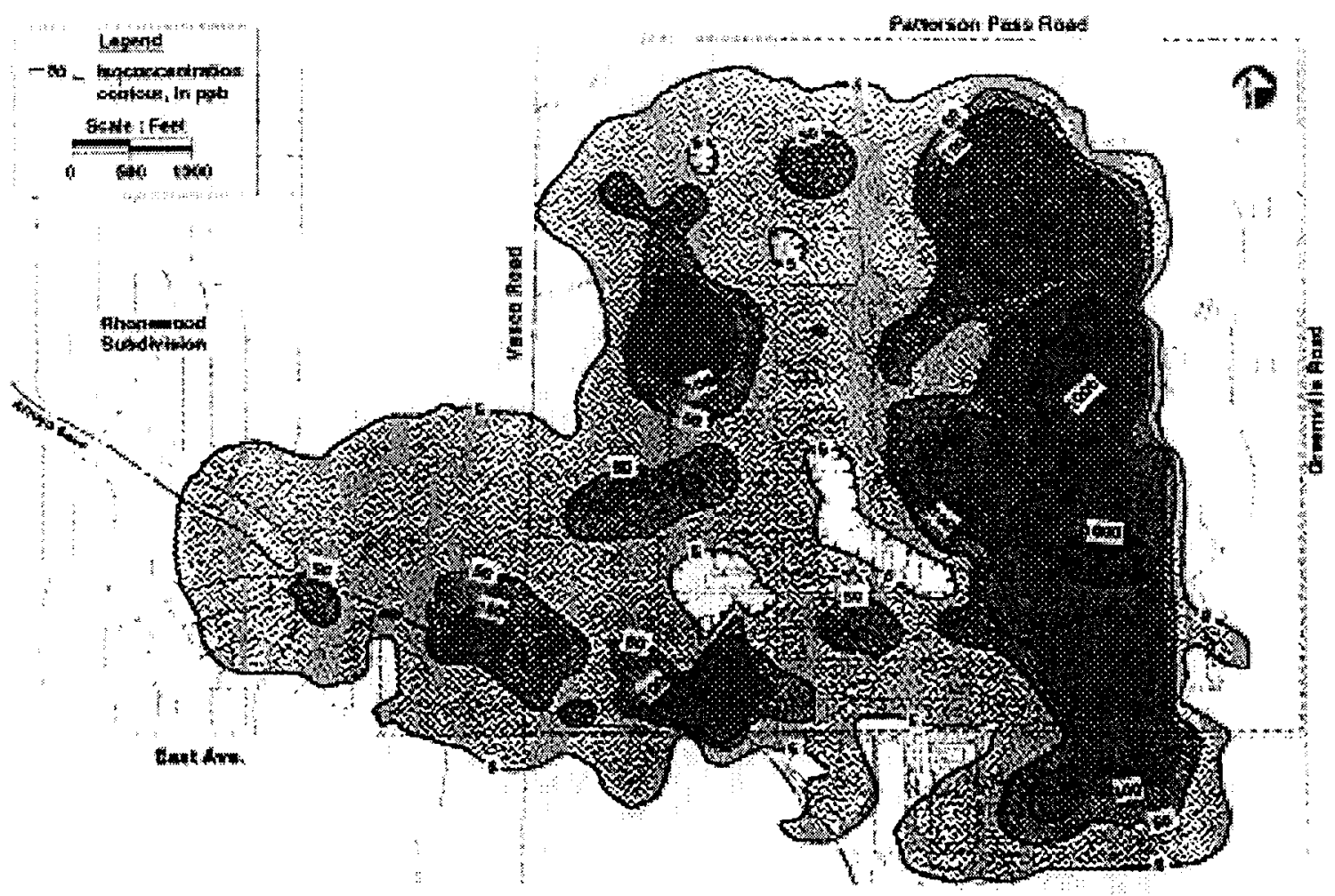

Fig. 1: The VOC plume on the LLNL site as of 1994. Our Accelerated Site Clean-up Initiative is designed to remove all or part of the eastern contaminant source region and achieve negotiated removal from the National Priorities List. 
have been found; these suggest the presence of DNAPL but no DNAPL has been definitively identified. Average concentrations in the source region are about $1 \mathrm{ppm}$. TCE is the primary VOC but PCE, DCE, chloroform, and other chlorinated solvents can also be found above MCLs. Pump-and-treat is the current method of remediation and, according to the early projection, is expected to take greater than 50 years; the 1995 Baseline Environmental Management Report (BEMR) estimated a $\$ 402 \mathrm{M}$ lifetime cost.

Our objective is to eliminate approximately $90 \%$ of the contaminant mass in the chlorinated solvent plume (Fig. 2). This targets the source region of the contaminant plume where total VOC concentrations can exceed $10 \mathrm{ppm}$ and which comprises over $10^{8}$ gallons of contaminated groundwater. There are four steps required to accomplish these objectives:

1) prevent further expansion of off-site plume toward drinking water wells,

2) prevent further migration of plume outside site boundaries,

3) eliminate the contaminant source regions which contribute most to the future expansion of the plume, and

4) prevent further migration of the source region during these accelerated operations The first two steps are adequately achieved by maintaining current pump-and-treat operations both off-site and at the western boundary. The last two require the application of aggressive new technologies.

\section{Plume Source Regions}

Often it is the complex heterogeneous nature of plume source regions that cause extended cleanup times (Fig. 3). Most of the plumes of interest, including the LLNL plume, occur in heterogeneous porous media. Though different types of heterogeneity exist, it is the extreme variation in hydraulic conductivity that causes the greatest problems. Hydraulic conductivity can range over 6 orders of magnitude or more from fine-grained silts and clays to the coarser and more

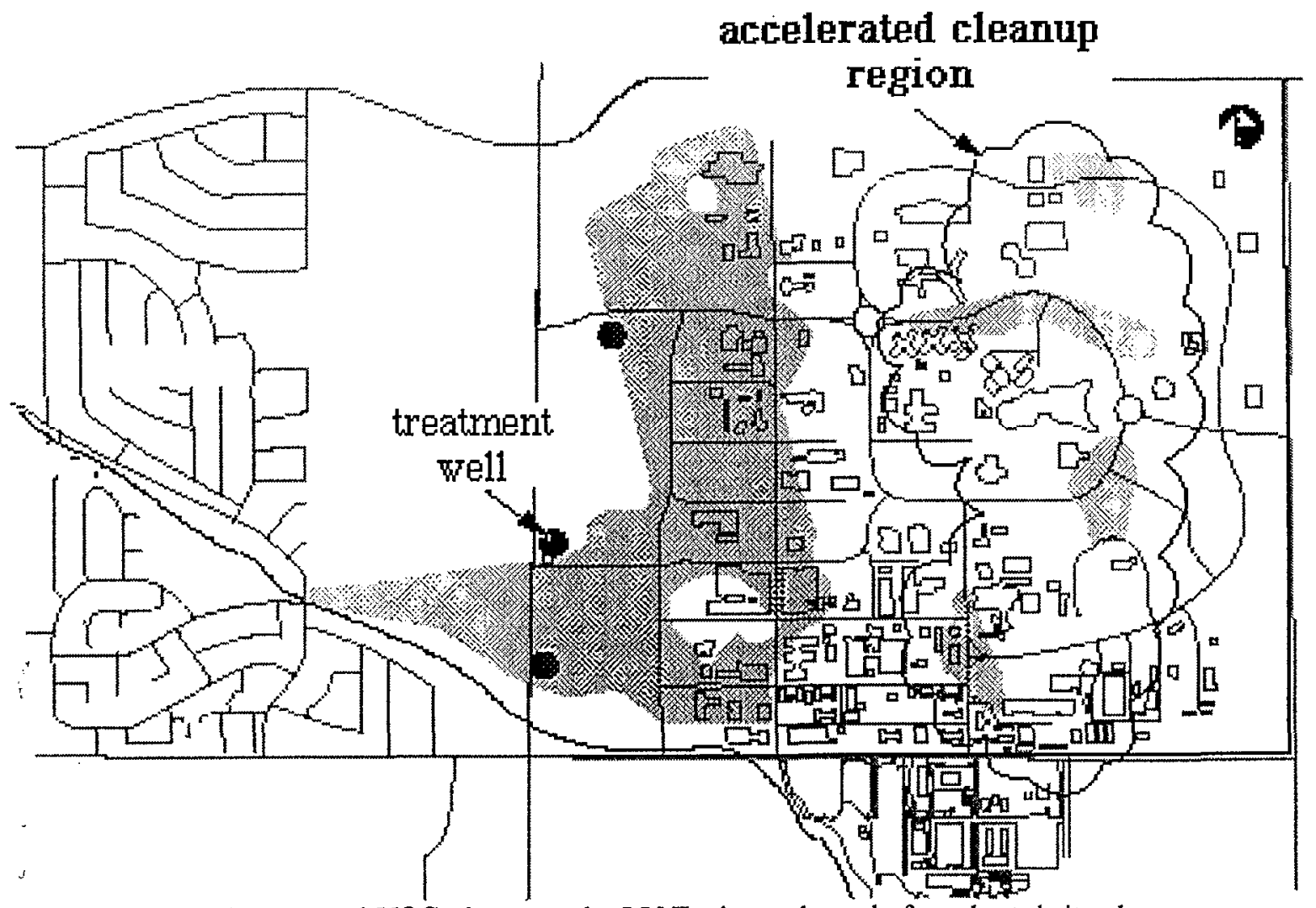

Fig. 2: The expected VOC plume on the LLNL site at the end of accelerated site cleanup, leading to negotiated closure and delisting from the National Priorities List. 


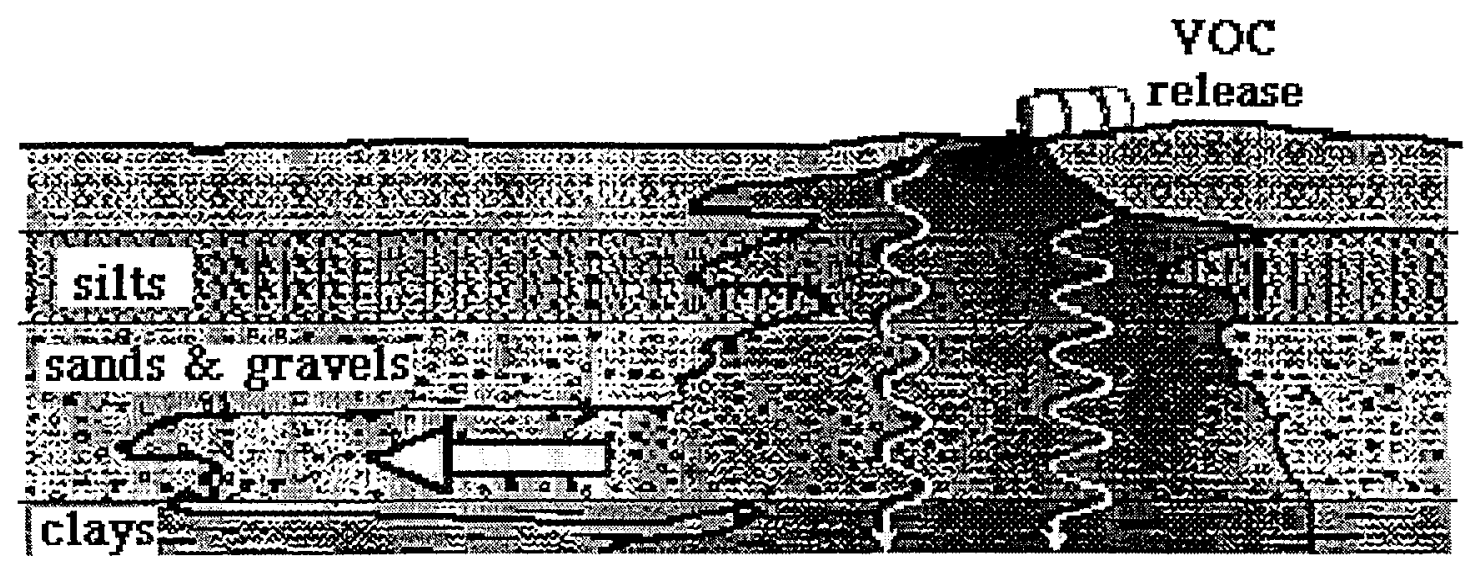

Fig. 3: Schematic of a contaminant plume in a heterogeneous porous medium. Typically, all units become contaminated.

permeable sands and gravels. In addition, these grain sizes comprise units which have variable and difficult to characterize thickness and areal dimensions.

Contaminants spilled on the surface will result in contaminated groundwater in most of these units. Fluid will percolate downward and through each unit in a complicated way. Ambient groundwater flow in the coarse-grained, high hydraulic conductivity units will spread the contamination downstream and, to a degree, dilute concentrations. Ambient transport in the finegrained units is low, so concentrations may remain high. Subsequent pump-and-treat actions are conducted preferentially in the high conductivity units, leaving the low conductivity units relatively untouched (Fig. 4). Diffusion or slow advection into the high conductivity units reduces concentrations in the fine-grained units while slowly increasing concentrations in the coarsegrained units. This causes an extended time where high volumes of low-contaminant concentrations are recovered. In the extreme, a site declared clean can rebound to its previous state of high contaminant concentrations in the sands and gravels as contaminants slowly move into these units.

A technology or suite of technologies must address contaminated groundwater in all contaminated units to accomplish the objective of rapid site cleanup.

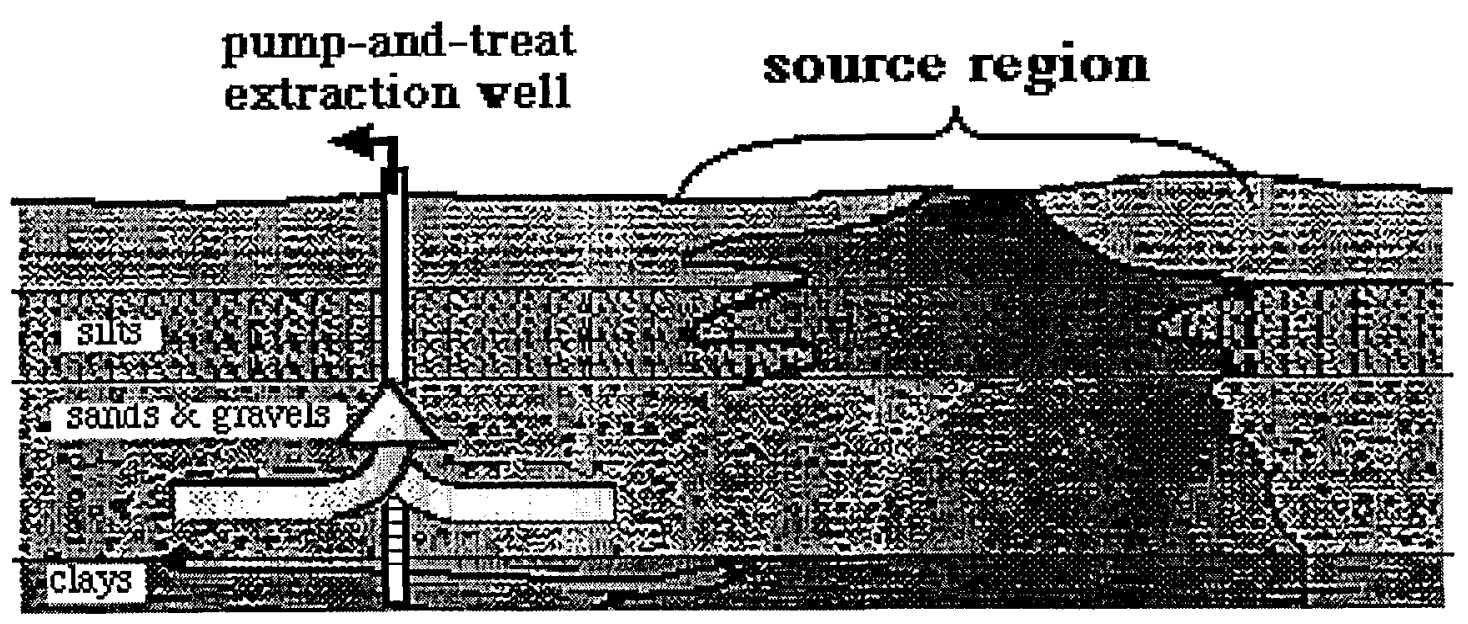

Fig. 4: Schematic of a contaminant plume in a heterogeneous source region after remediation by pump-and-treat. Pump-and-treat preferentially extracts groundwater from the units with the greatest hydraulic conductivity, usually the sands and gravels. Contaminated groundwater remains in the lower conductivity units - the clays and silts. Over time, the contaminants slowly diffuse or flow into the previously clean units, extending the remediation time or even causing a rebound to preremediation concentrations. New techniques must be employed to clean the entire subsurface. 


\section{System of Technologies}

\section{Hydrous Pyrolysis/Oxidation}

We have evaluated candidate technologies and the following selection criteria have been applicd to meet our remediation objectives:

- in situ and non-extractive

- operable at depths averaging $125 \mathrm{ft}$.

- effective in the saturated zone

- rapid contaminant destruction:

- for concentrations exceeding $10 \mathrm{ppm}$

- to reduce concentrations to MCLs

- for large volumes

- deployable at commercial scale within 2 to 3 years

Hydrous pyrolysis/oxidation is the only technology that meets all of the required criteria. It operates by injecting steam and oxygen to provide heat and an adequate supply of an electron donor. When the steam zone collapses upon cessation of injection, contaminated groundwater flows back into the heated region and contaminants are rapidly destroyed. The injection of large volumes of steam has been accomplished for decades in the petroleum industry. Our previously funded laboratory program has demonstrated that the process can operate very effectively at high temperatures and high dissolved oxygen concentrations. The process may have operated at the LLNL Dynamic Underground Stripping operation where 1,2 DCA was reduced to nondetectable concentrations after operations. We have designed a brief laboratory program to gain further rate information to enhance the engineering design of the field process.

\section{In Situ Microbial Filters}

Technologies to contain the source region and prevent its expansion are required during the application of hydrous pyrolysis/oxidation. The injection of large volumes of steam will accelerate contaminant migration and be a force for source region dispersal (Fig. 5). We have evaluated both extractive and permeable barrier candidate technologies and, in general, the large volumes of groundwater required to be treated over a short period of time due to the injection of large quantities of steam preclude the deployment of extractive technologies. The following selection criteria have been applied to meet our remediation objectives:

- in situ and non-extractive

- operable at depths averaging $125 \mathrm{ft}$.

- effective in the saturated zone

- rapid contaminant destruction for large fluxes of dilute contamination

- deployable at commercial scale within 2 - 3 years

In situ microbial filters is the only evaluated technology that meets all of the criteria. This bioremediation, permeable barrier technology operates by the injection of bacteria cells without any growth substrates or electron donors. A portion of the injected cells attach to the soil and form a deep bed, reactive filter. Injection is short term and contaminated groundwater flows through the filter region once injection has terminated, the flow being forced by upstream steam injection. The absence of growth substrates requires that the filter be replenished after a period of time. The replenishment interval determines its economic effectiveness. This technology was designed for the exact conditions expected in this application, in situ destruction of moderate to low level concentrations of chlorinated solvents in a rapid groundwater flow environment. This unique approach has been applied in a small-scale field test at a TCE plume in Chico, CA. Groundwater with $>400 \mathrm{ppb}$ TCE was reduced to $10 \mathrm{ppb}$ TCE and remained there for about 60 hours.

\section{Process Monitoring}

Successful remediation is only partly dependent upon good cleanup technology. Treatment technologies that will target contaminant sources as part of this initiative require an advanced level 
of monitoring for process control and performance assessment. Experience gained in monitoring other subsurface treatment tests will be used in process design and optimization for this project. In the Dynamic Underground Stripping Project, for example, the rapid response of the monitoring methods provided near-real time information about the thermal processes, thereby allowing engineers to effectively control the subsurface operations. Initial field applications in this project will be heavily instrumented to provide a detailed understanding of the subsurface processes as the overall operational strategy is optimized. With increased field experience, subsequent full-scale monitoring designs will be streamlined, reflecting both the experience gained from the initial applications and the concurrent development of systems tailored to the project operational needs.

Cleanup methods are only as good as the ability to 1) place them where needed, 2) determine whether they are operating effectively, and 3) demonstrate regulatory compliance. Real-time process control systems will monitor steam injection, in situ oxygen levels, ground water flow, and in situ biofilter operation. Electrical Resistance Tomography, with its demonstrated ability to provide timely images of underground processes, will be a key tool for monitoring steam and biofilter operations. Fiber optic chemical sensors will be used in conjunction with the cleanup methods to monitor water chemistry for controlling oxygen- and microbe-injection processes. Tiltmeters will be used for large-area hydraulic control of steam injection and pumping processes.

Areas of the subsurface that are missed initially by thermal treatment will be identified through tomography and tiltmeter measurements and targeted for further operations. This will provide evidence to the regulators that the cleanup processes are directed by knowledge of underground processes and mechanisms and not only by concentrations of contaminants in well samples. This type of feedback was extremely successful at the gasoline spill site in gaining regulatory support for innovative clcanup processes.

\section{Contaminant Targeting}

The effectiveness of remediation techniques is strongly improved by characterization information that allow contaminants to be targeted for cleanup. Using stratigraphic correlation



Fig. 5: Illustration of the displacement of contaminated groundwater caused by injection of large volumes of steam. To prevent dispersal of the contaminant source region, we propose to emplace in situ microbial filters downstream of the steam injection wells; these permit flow of groundwater but destroy contaminants as they pass through them. 
methods from petroleum geology in concert with comprehensive characterization data from LLNL site investigations, we now understand the site well enough to accurately predict, for engineering purposes, where contaminants are located and where they are likely to be transported. This understanding allows contaminants in existing plumes to be tracked back to their highconcentration source areas. Consequently, instead of having to apply costly remediation methods to the entire site, source areas can now be targeted for treatment with appropriate cleanup methods (Fig. 6). Although many borings have been drilled at the LLNL site, it is the application of correlation techniques rather than the amount of data that allows long-distance interpolation and identification of connections between observed subsurface layers. These techniques should be used to similar effect at other sites that are less well characterized.

Soil beneath one million square yards of the LLNL site is contaminated to some extent. Over 60 million cubic yards of earth are encompassed between the ground surface and the maximum depth of contamination beneath LLNL and adjacent contaminated areas. Although conventional characterization efforts indicate that only about $1 / 3$ of that area contains significant concentrations of contaminant (greater than $50 \mathrm{ppb}$ ), advanced contaminant targeting concepts have determined that contaminants reside in an average thickness of only 12 yards of soil. This recently achieved understanding allows cleanup technologies to be focused on a well defined, relatively small volume of soil (about 5 million cubic yards of earth) rather than having to treat the entire 60 million cubic yard volume bencath the LLNL site.

\section{Comprehensive Team Approach}

The traditional technology development to commercial deployment approach consists of six sequential steps (Fig. 7). However, there are obstacles and even complete breaks at key points in this sequence. In the following paragraphs, these steps and obstacles will be described as well as our thoughts on a new approach to commercialization.

Basic laboratory research is conducted to provide a fundamental understanding of a given contaminant destruction or removal process and also to obtain values for key parameters (Basic

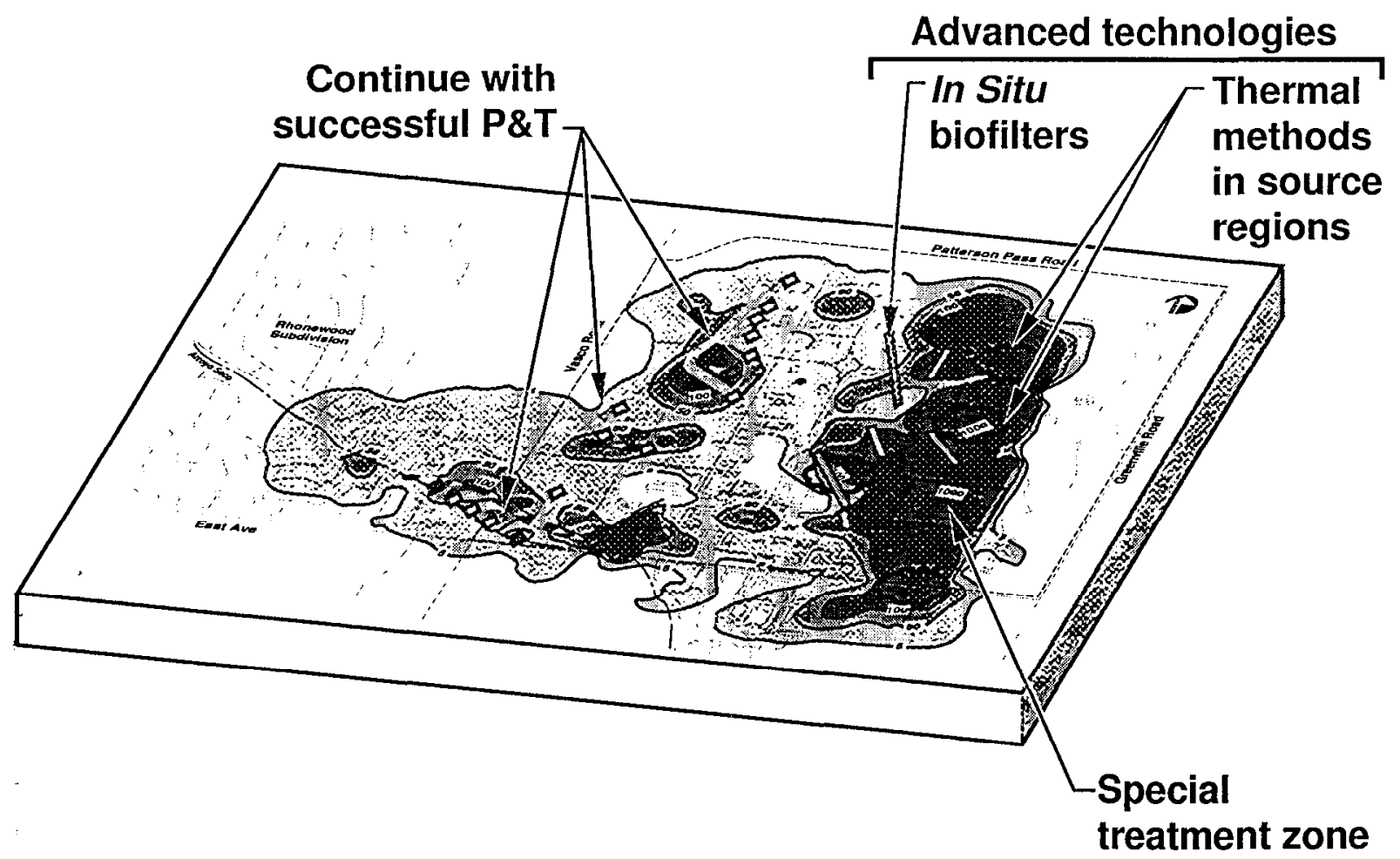

Fig.6: Illustration of one possible synergistic deployment of pump-and-treat (as a boundary control) and new technologies (as source elimination) to accelerate closure of an NPL site. 
Research). Ideally, the chosen research topic originates from a property owner who has a difficult remediation problem. This step takes a relatively small amount of money and occurs at the principal investigator level. Once this is completed, then the process must be developed into an actual remediation system - one that is capable of operating in the field (System Development). Though a critical step, this phase is often under-valued, under-supported, and inadequately developed; it's a long way from the test tube to the well-head. The obstacle for system development involves the transition from an individual researcher to an interdisciplinary team and the associated increased financial commitment. With the development of a remediation system, then a small-scale, scientific field test can be conducted (Field Demonstration). The objective is to demonstrate that the both the contaminant destruction process and remediation system concept work; for groundwater treatment operations, small-scale is approximately 1,000 gallons or less.

In some industries, a successful field test at this scale is sufficient to make a commercialization decision. However, the environmental restoration industry is risk averse and undercapitalized; a greater degree of technology development and risk reduction is required to decrease the investment level and pay-out time. At least one Pilot-Scale Field Test (approximately 100,000 gallons) is needed to collect sufficient information to ensure technical success, financial competitiveness, and regulatory acceptance and to define the application niche. It is at this step that a break occurs in the technology commercialization cycle; neither government nor industry are currently funding tests at this scale.

Even with a successful pilot-scale field test completed, there are obstacles to taking the next step, Commercial Acquisition of the new technology. A lack of knowledge and experience with the new technology, tight investment funds, and an excessive time lag to deployment comprise this obstacle in the environmental industry. The restoration firm must gain the technical expertise, which may involve license payments and the hiring of new personnel; they must acquire needed

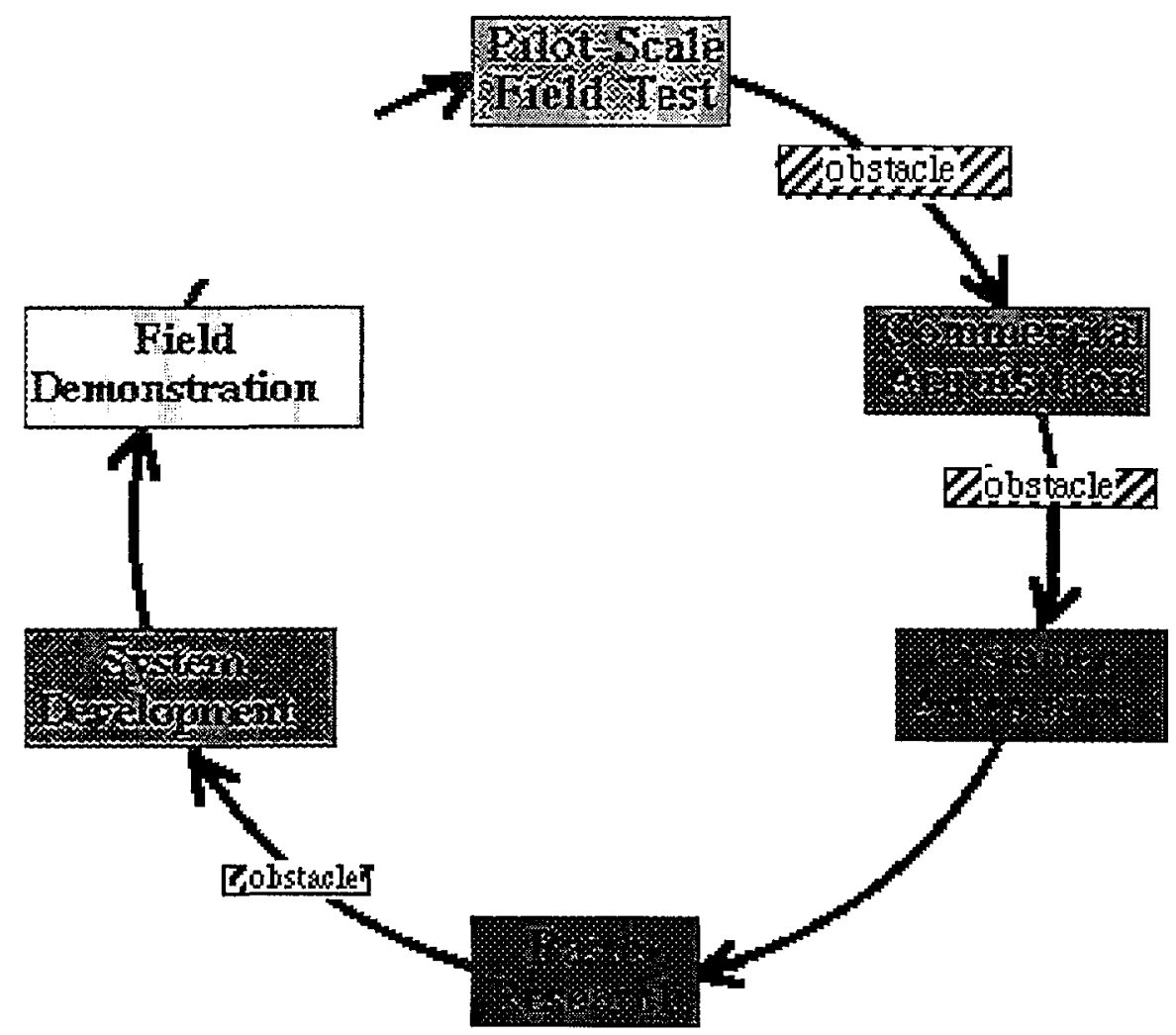

Fig. 7: The technology development and commercial deployment cycle showing the six key elements with the relative amount of funds required for each, three major obstacles which occur when information transmittal occurs to a new group, and one major break; very few pilot-scale tests are conducted due to their expense and scale. 
equipment and instruments. Finally a firm with a new technology must have a willing customer base which is the obstacle to the final step of technology deployment. From the customers perspective, they may face decision of changing in-place remediation agreements (RODs) and a decision of spending more money in a shorter period of time to reduce the total duration and lifecycle costs of the remediation effort.

We seek to develop an improved process that begins to overcome these obstacles. Instead of a sequential process, we envision an approach which simultaneously solves the key tcchnical, commercial, and regulatory problems. Though we do not clearly see how to accomplish this, we expect that it will involve some level of direct participation and investment in the technology development phase by environmental restoration firms, potential customers, and large manufacturing firms who, because of their liability position, have an in-house restoration staff. Participation may occur individually, as consortia, or as some other type of partnership. 


\section{Hydrous Pyrolysis/Oxidation}

\section{Introduction}

Hydrous pyrolysis/oxidation is an innovative process for the in situ destruction of solvents. The technique is expected to be applicable to DNAPLs (dense nonaqueous phase liquids) and dissolved organic components. These chemicals rapidly oxidize to carbon dioxide and chloride ions when heated to temperatures near the boiling point of water, provided sufficient dissolved oxygen or soil mineral oxidants are present. The method utilizes the established experience in heating large volumes of ground, developed in the Dynamic Underground Stripping Demonstration, to provide the delivery system for the heat and oxygen. Steam and oxygen are injected together, building a heated, oxygenated zone in the subsurface. When injection is halted, the steam condenses and contaminated groundwater returns to the heated zone. It mixes with the condensate and oxygen, destroying any dissolved contaminants. This avoids many of the mixing problems encountered in other in situ oxidation schemes. DNAPL may be destroyed in place, without surface treatment. This method takes advantage of the much more rapid chemical reactions which occur at steam temperature, as well as the large increase in mass transfer rates which make contaminant more available for destruction.

We are investigating the in situ thermal degradation of chlorinated hydrocarbons (TCE, PCB, pentachlorophenol, etc.) and refractory hydrocarbons (PAHs) via this method. Chlorinated solvents comprise the bulk of the hazardous waste contamination throughout the DOE complex. We are studying degradation rates at temperatures achieved by thermal remediation techniques and methods to catalyze the chemical processes to maximize degradation. We are investigating the impact of the soil heating and the degradation products of the chlorinated hydrocarbons on soil mineral stability, as it relates to clean-up performance.

This approach will dramatically improve the rate and efficiency of remediation by rendering the hazardous materials into benign ones via a completely in situ process. In preparation for follow-on work testing this method in the field, we are developing a concept for the implementation of hydrous pyrolysis/oxidation through co-injection of steam and small amounts of oxygen, as well as evaluating the rate at which hydrous pyrolysis/oxidation occurs due to the natural presence of mineral oxidants such as manganese oxides when the water temperature is raised. We are also determining the thermodynamic properties (e.g., solubility, Henry's Law constants, etc.) of these hazardous compounds, as a function of $\mathrm{T}$ and $\mathrm{P}$, in order to be able to predict effectiveness and required time for design purposes and to optimize clean-up through the use of process-oriented hydrologic transport and geochemistry models. In spite of recent advances in modeling capabilities, the thermodynamic data necessary to make design calculations for elevated temperatures are essentially nonexistent.

\section{Chemical Basis for In Situ Destruction}

LLNL has pioneered the study of in situ oxidation of contaminants through an EM50 and internally-funded research effort in the in situ thermal degradation of petroleum distillates (gasoline, diesel fuel, PAHs etc.) and chlorinated hydrocarbons (TCE, TCA, PCB, etc.) via hydrous pyrolysis/oxidation. These types of materials comprise the bulk of the hazardous waste contamination throughout the DOE complex. We are studying the base rates of degradation at temperatures achieved by thermal remediation techniques and methods to catalyze the chemical processes to maximize degradation, and we are investigating the wider implications of both the required heating and the degradation products of the petroleum distillates and chlorinated hydrocarbons on soil mineral stability and its effect on clean-up performance. This method provides the basis for dramatically improving the rate and efficiency of remediation by rendering the hazardous materials into benign ones via a completely in situ process, and is described in this section.

Background: Several in situ methods for cleaning-up volatile organic contaminants involve the application of either heat alone or heat plus water and/or steam to mobilize organic contaminants. 
This approach is essentially based on the physical properties of the VOCs. As the name implies, they volatilize easily. A fact that is less well recognized, however, is that organics are increasingly solvated by and reaclive with water as temperature is increased. Increased solvation occurs largely as a consequence of the precipitous drop in the dielectric constant of water as temperature increases. Water becomes a progressively better and better solvent for organics with increasing temperature. Under appropriate conditions, water can react with hazardous organics to produce a relatively benign mixture of oxygenated compounds (principally $\mathrm{CO}_{2}$, but potentially also alcohols, aldehydes and/or carboxylic acids). The yield of benign products resulting from the hydrothermal oxidation of hazardous organics may be enhanced using a variety of oxidants.

Over the last several years we have developed hydrothermal equipment and analytical capabilities ideally suitcd to investigating the reaction of solid, liquid and gaseous hydrocarbons and chlorinated hydrocarbons with water under conditions ranging from room temperature and pressure up to $450^{\circ} \mathrm{C}$ and $2 \mathrm{~kb}$. We have used this equipment to study the reaction of kerogen contained in oil shale with water to produce carboxylic acids and to study the interaction between the organic acids and reservoir minerals [Knauss et al., 1992; Knauss and Copenhaver, 1995a], to study the cracking of petroleum under both hydrous and anhydrous pyrolysis conditions [Jackson et al., 1992], to study the hydrous pyrolysis of organic solvents (including both chlorinated hydrocarbon and petroleum distillate based products) in the presence and absence of silicate minerals and, most recently, to make the measurements of the solubility of p-xylene as a function of temperature and pressure [Knauss and Copenhaver, 1995b]. These latter two studies bear directly on the preliminary results with TCE oxidation and solubility.

Our prior experimental work with organic solvents suggested that in situ thermal degradation of VOCs via hydrous pyrolysis forms the basis for a whole new remediation method. Preliminary results of hydrothermal oxidation using both dissolved $\mathrm{O}_{2}$ gas and mineral oxidants present naturally in soils, e.g., $\mathrm{MnO}_{2}$, demonstrate that TCE can be rapidly and completely degraded to benign products at moderate conditions which are easily achieved in thermal remediation (Fig. 8). Our objective is to accelerate the reactions in ways that result in maximum rates of destruction of the hazardous parent compounds and that favor reaction paths leading to the production of only benign products.

Experimental approach: We use laboratory static autoclave and core-flood experiments to determine the optimum chemical conditions for remediating contaminants via hydrous pyrolysis. The initial phase of experimental work is used as a vehicle for designing an in situ thermal remediation technique applicable to hydrocarbons and halogenated hydrocarbons. We also
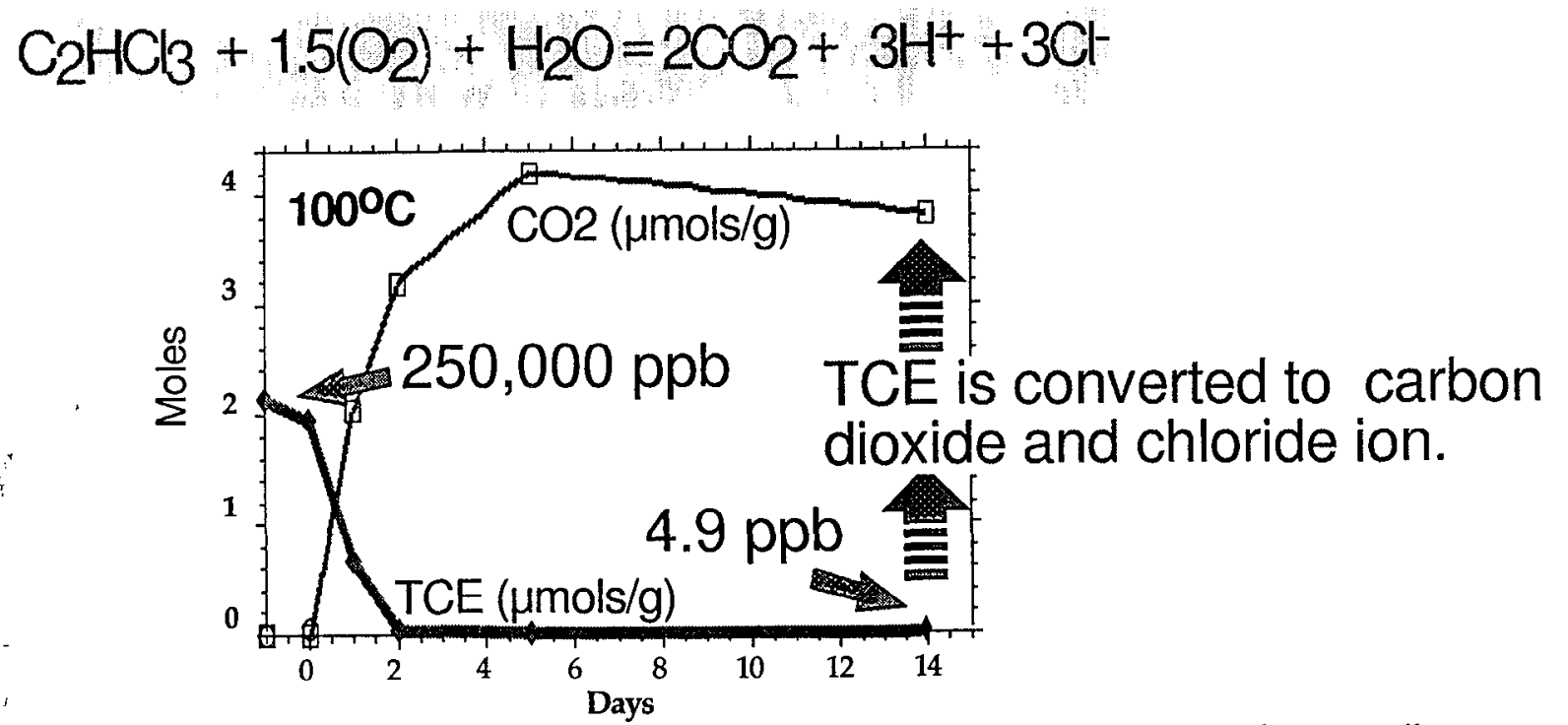

Fig. 8: Laboratory results show that TCE can be rapidly destroyed at temperatures that are easily achieved by steam injection . 
simulate the field treatment process in the laboratory to measure the impact of treatment on soil transport properties and fluid chemistry, and to identify the organic/aqueous fluid-solid reactions that occur.

The static autoclave experiments are run in Dickson-type, gold-bag rocking autoclaves. The reaction vessels use a flexible gold bag sealed with a high purity titanium hcad and are contained within a large steel pressure vessel. Their design allows periodic sampling of the reaction cell under in situ conditions throughout the course of an experiment without disturbing the temperature and pressure of the run. During the experiment the solution contacts only Au and carefully passivated Ti so that unwanted surface catalytic effects are eliminated. We may, however, introduce any combination of solid, liquid or gaseous catalysts or oxidants into the reactors in order to study their effects on reaction mechanisms and rates. We also use fixed volume autoclaves constructed entirely of high purity titanium to conduct two phase (liquid/vapor) experiments. The sampled fluids and gases are analyzed using a variety of analytical techniques including: ICP-ES, IC, GC (using purge and trap) and HPLC.

The core flood experiments are run in a flow-through apparatus capable of sustaining fluid flow at temperatures and pressures as high as $350^{\circ} \mathrm{C}$ and 500 bars. All fluid wetted components are composed of non-reactive Teflon, titanium, inconel, stellite or viton. Variations in effluent fluid chemistry record the reactions occurring during the core-flood. The apparatus is currently configured to conduct water-flood experiments with the ability to use different starting fluid compositions, but may be modified to conduct steam-flood experiments. Cores may consist of either intact rock or packed alluvium. Cores are fully characterized, both physically and chemically, before and after the core-flood.

As described below, there are almost no data on the elevated temperature thermodynamic properties of the hydrocarbons or halogenated hydrocarbons. Fortunately, slight modification of the static autoclaves makes them ideal for determining liquid phase solubility, Henry's Law constants and solid-liquid distribution coefficients $\left(\mathrm{K}_{d} \mathrm{~s}\right)$ for hydrocarbons and halogenated hydrocarbons.

Theoretical basis: The biologically-based efforts in the reduction of chlorinated compounds are based on the ability of some enzyme systems to drive reactions energetically "uphill". Although reduction VOCs is not favored under most near-surface conditions, organisms can rapidly reduce some chlorinated hydrocarbons to eliminate their toxicity. Iydrous pyrolysis/oxidation, like the methanotrophic-based reactions used in the in situ microbial filters approach, destroys contaminant compounds using the thermodynamically-favored pathway of oxidation. Although these can be much slower, added heat makes them occur at satisfactory rates.

Recently, [Dolfing and Janssen, 1994] used group contribution estimation techniques to calculate the free energies of formation of the aqueous and gas phase aliphatic chlorinated hydrocarbons. The estimates are for $25^{\circ} \mathrm{C}$ and one bar. Using these data, we can write possible hydrolysis and oxidation reactions involving compounds like TCE and calculate their thermodynamic driving force.

We made such calculations for a number of potentially interesting reactions and found that for many of them, at $25^{\circ} \mathrm{C}$, there was a significant driving force. This fact alone, of course, doesn't mean that the reaction will, in fact, proceed as written for a number of reasons. First, this is an estimate of the thermodynamic driving force for the reaction at reference state conditions of temperature and pressure and with unit activities and fugacities for all species in the reactions. Second, we are not considering any kinetic inhibition of the reactions. Nevertheless, the calculations are a starting point for our discussion.

Consider the following aqueous and gas phase reactions $\left(\right.$ at $25^{\circ} \mathrm{C}$ ) involving TCE: Aqueous Phase Oxidation:

$2 \mathrm{C}_{2} \mathrm{Cl}_{3} \mathrm{H}(\mathrm{aq})+3 \mathrm{O}_{2}(\mathrm{aq})+2 \mathrm{H}_{2} \mathrm{O}=4 \mathrm{CO}_{2}(\mathrm{aq})+6 \mathrm{H}^{+}+6 \mathrm{Cl}^{-}$

$\Delta \mathrm{G}_{\mathrm{rxn}}=-467.9 \mathrm{kcal} / \mathrm{mol}$

Gas Phase Oxidation:

$2 \mathrm{C}_{2} \mathrm{Cl}_{3} \mathrm{H}(\mathrm{g})+3 \mathrm{O}_{2}(\mathrm{~g})+2 \mathrm{H}_{2} \mathrm{O}(\mathrm{g})=4 \mathrm{CO}_{2}(\mathrm{~g})+6 \mathrm{HCl}(\mathrm{g})$

$\Delta \mathrm{G}_{\mathrm{rxn}}=-414.1 \mathrm{kcal} / \mathrm{mol}$ 
Heterogeneous Oxidation by Manganese Oxide:

$$
\begin{aligned}
& \mathrm{C}_{2} \mathrm{Cl}_{3} \mathrm{H}(\mathrm{aq})+3 \mathrm{MnO}_{2}(\mathrm{~s})+3 \mathrm{H}^{+}=2 \mathrm{CO}_{2}(\mathrm{aq})+3 \mathrm{Mn}^{+2}+2 \mathrm{H}_{2} \mathrm{O}+3 \mathrm{Cl}^{-} \\
& \Delta \mathrm{G}_{\mathrm{rxn}}=-228.1 \mathrm{kcal} / \mathrm{mol} \\
& \text { Heterogeneous Oxidation by Iron Oxide: } \\
& \mathrm{C}_{2} \mathrm{Cl}_{3} \mathrm{H}(\mathrm{aq})+3 \mathrm{Fe}_{2} \mathrm{O}_{3}(\mathrm{~s})+9 \mathrm{H}^{+}=2 \mathrm{CO}_{2}(\mathrm{aq})+6 \mathrm{Fe}^{+2}+5 \mathrm{H}_{2} \mathrm{O}+3 \mathrm{Cl}^{-} \\
& \Delta \mathrm{G}_{\mathrm{rxn}}=-164.9 \mathrm{kcal} / \mathrm{mol}
\end{aligned}
$$

Under the conditions of temperature, pressure and activity/fugacity implied in the calculation, all these reactions have a significantly negative free energy of reaction, i.e., they are energetically favored. Under the conditions prevalent in most of the biosphere, there is a large driving force favoring the oxidation of TCE and other volatile organic compounds.

Similar reactions may be written for many other aliphatic chlorinated hydrocarbons (e.g., Chloroform, cis-1,2-DCE, PCE, Carbon Tetrachloride, 1,2-DCA, TCA, etc.). We have performed these calculations as well. The results encouraged us to pursue experiments to investigate the hydrous pyrolysis/oxidation of TCE.

It is reasonable to ask why experiments of this kind have not been conducted in the past. We believe that the detailed geochemical analysis available through the use of the Dickson autoclaves, coupled with the prospect of economically heating large volumes of the subsurface, have uniquely coincided at this time. The potential for oxidizing these compounds is now obvious (only recently, owing to a lack of thermodynamic data precluding calculations), but the rate at ambient conditions is negligible. Any oxidation that does occur results in benign products, which are not detectable in natural systems. The activation barriers are too large for simple chemical oxidation to be significant at $20^{\circ} \mathrm{C}$. Many natural biological systems utilize the reductive destruction of these compounds, resulting in observable products such as vinyl chloride and leading to the incorrect impression that reductive dehalogenation is a favored process. The principal limitation to biological destruction of TCE, either by oxidative or reductive mechanisms, is that the TCE must be dissolved and in low-enough concentrations to be non-toxic to the microbe.

Results: In all of these preliminary experiments, wc have used very high concentrations of TCE (up to $600 \mathrm{ppm}$ ) much higher than many typical contaminated sites. We wished to confirm that our approach would be feasible in the worst possible situations and by starting with high initial TCE concentrations, we also hoped to be able to detect reaction products resulting from alternative chemical pathways. Because these runs are in closed systems, initially, we have effectively loaded an excess of dissolved $\mathrm{O}_{2}$ gas into the gold bag. This is accomplished by introducing a few $\mathrm{ml}$ of $\mathrm{O}_{2}$ gas at 500 psi into the bag, letting it equilibrate at $500 \mathrm{psi}$ overnight, and then removing the excess gas, yielding a single liquid phase. The experiment is then run at 500 psi total pressure. The runs with solid $\mathrm{MnO}_{2}$ only contained an amount of dissolved $\mathrm{O}_{2}$ appropriate for air saturated water, i.e., approximately $8 \mathrm{ppm}$.

We have completed runs at $150,107,100,92,85,75$ and $50^{\circ} \mathrm{C}$. We have found that dissolved $\mathrm{O}_{2}$ gas can rapidly and completely destroy TCE, producing benign products (predominantly $\mathrm{CO}_{2}$ and $\mathrm{Cl}^{-}$anion), at temperatures easily achieved in potential in situ thermal remediation techniques. At temperatures over approximately $90^{\circ} \mathrm{C}$ the TCE is completely removed to detection limits in one to a few days, depending on the temperature. The TCE concentration in these particular runs with high starting concentrations decreased at least 10,000-fold. The products are those expected for complete oxidation to $\mathrm{CO}_{2}$.

As an example, in Fig. 9 we show the results from the $107^{\circ} \mathrm{C}$ run (TCE-10). After 14 days, the TCE concentration was reduced from $530,000 \mathrm{ppb}$ to $4.9 \mathrm{ppb}$. The only other run product detected using the EPA $601 \mathrm{GC}$ method was $429 \mathrm{ppb}$ chloroform, which represents a yield of $0.09 \mathrm{~mol} \%$. The dominant products were $\mathrm{CO}_{2}$ (yield $=93 \mathrm{~mol} \%$ ) and $\mathrm{Cl}$ anion (yield $=91 \mathrm{~mol} \%$ ), although a small amount of formic acid was also detected.

The production of a small amount of chloroform does not appear to be of concern, because the chloroform itself should be oxidized, although at a slower rate than TCE. Consider the following reaction:

$$
\begin{aligned}
& 2 \mathrm{CCl}_{3} \mathrm{H}(\mathrm{aq})+\mathrm{O}_{2}(\mathrm{aq})+2 \mathrm{H}_{2} \mathrm{O}=2 \mathrm{CO}_{2}(\mathrm{aq})+6 \mathrm{H}^{+}+6 \mathrm{Cl}^{-} \\
& \Delta \mathrm{G}_{\mathrm{rxn}}=-231.5 \mathrm{kcal} / \mathrm{mol}
\end{aligned}
$$


Again, whether or not the chloroform is oxidized in a specific situation depends not on the free energy for this reaction at reference state conditions of temperature and pressure and unit activities for all aqueous spccies but, rather, for the actual temperature and pressure and the actual activities of dissolved aqueous species.

The runs at temperatures below approximately $90^{\circ} \mathrm{C}$ produced the same products, but the rates of TCE degradation were considerably slower. We are continuing to make oxidation rate measurements as a function of temperature in order to determine the activation energy of the reaction. Then we can calculate precisely the rate of TCE oxidation by $\mathrm{O}_{2}$ gas at any temperature of interest.

Note that soils have considerable buffer capacity, and the trivial amount of acid produced in these experiments would be rapidly consumed by the feldspar minerals present in soils and the soil or groundwater would not become appreciably acidic in the field. Our experiments are conducted in non-reactive hydrothermal systems, so that we can avoid complications due to experimental artifacts from catalysis by the equipment itself, and can precisely control both temperature and pressure. Many samples can be taken as the reaction proceeds without affecting the conditions of the reaction itself. This allows us to detect the exact reaction mechanisms, as shown on the figures, which involve the production of $\mathrm{H}^{+}$ion.

Oxidation via coupled $\mathrm{MnO}_{2}$ reduction: We have also investigated the oxidation of TCE by mineral phases common in soils in the absence of excess dissolved $\mathrm{O}_{2}$ gas at 100 and $150^{\circ} \mathrm{C}$. The soil mineral $\mathrm{MnO}_{2}$ can also oxidize TCE, again producing benign products $\left(\mathrm{CO}_{2}, \mathrm{Cl}^{-}\right.$anion and $\mathrm{Mn}^{+2}$ cation). However, at a given temperature the $\mathrm{MnO}_{2}$ rate of TCE oxidation is much slower than oxidation via dissolved $\mathrm{O}_{2}$ gas. This is at least partly due to the reaction being limited by the total surface area of the $\mathrm{MnO}_{2}$. In these initial experiments we used a very well crystallized mineral (pyrolusite) with very low specific surface area. Soil $\mathrm{MnO}_{2}$ would be expected to be much more reactive. This would suggest that in a field application even those more distal areas, too far away to benefit directly from the injection of $\mathrm{O}_{2}$ gas into a TCE "hotspot", would experience TCE degradation, because oxidants like $\mathrm{MnO}_{2}$ are ubiquitous in soils. All that's needed is heat and time. Since the earth is an excellent insulator, heated areas will stay warm for many years. Even at comparatively low rates, mineral oxidation can be an important polishing step in a remediation

TCE10: $\mathrm{TCE}+\mathrm{O}_{2}(\mathrm{aq})$ at $107^{\circ} \mathrm{C} \& 500$ psi

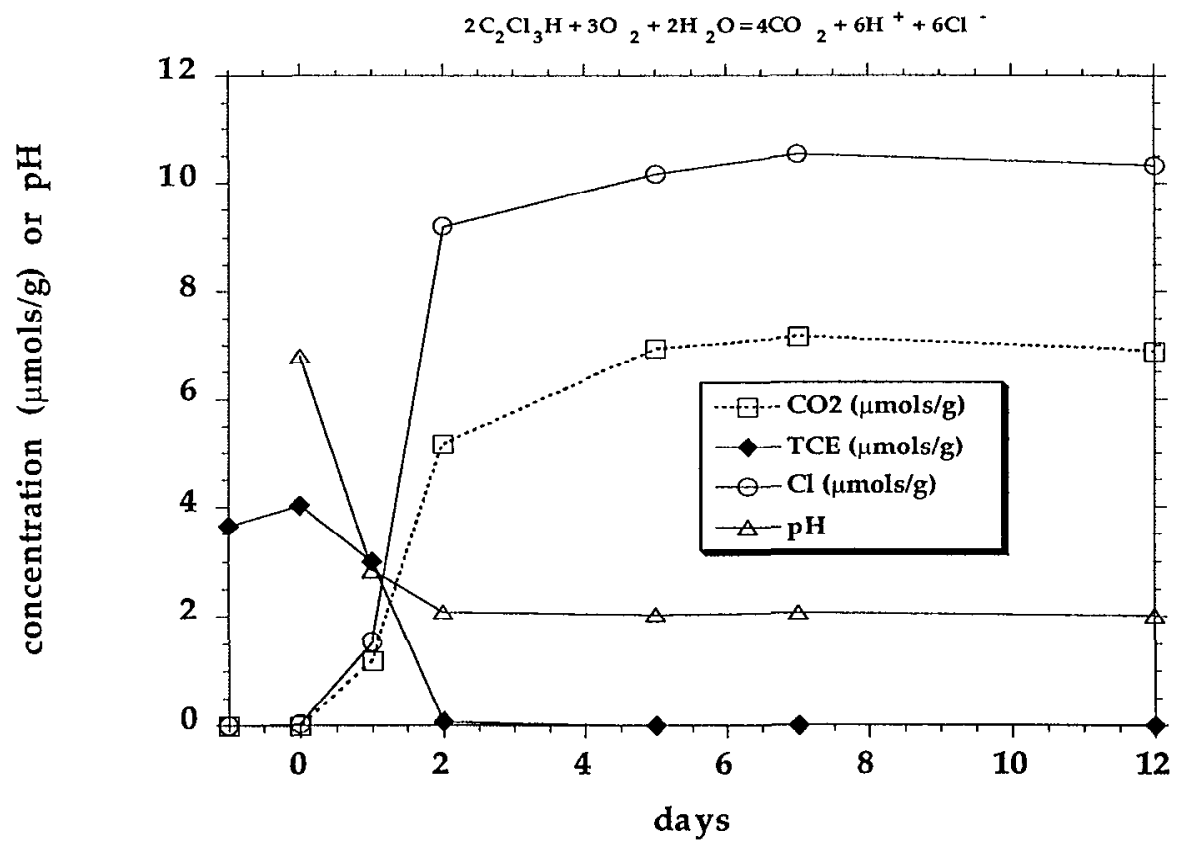

Fig.9. Oxidation of dissolved TCE by dissolved $\mathrm{O}_{2}$ gas at $107^{\circ} \mathrm{C}$ and $500 \mathrm{psi}$. 
scheme. Residual TCE (such as trapped in zones initially not heated) will eventually be oxidized.

As an example, in Fig. 10 we show the results from the $150^{\circ} \mathrm{C}$ run (TCE-5). Whereas the TCE was completely oxidized by excess dissolved $\mathrm{O}_{2}$ gas in a matter of 1 or 2 days at this temperature, almost $20 \%$ of the initial TCE remains unreacted after approximately 60 days in the presence of $\mathrm{MnO}_{2}$. However, even at this slower rate almost $2 \mathrm{ppm}$ per day of TCE was being destroyed by a mineral phase that is common at the LLNL site. By $100^{\circ} \mathrm{C}$ the rate of TCE oxidation by $\mathrm{MnO}_{2}$ has slowed considcrably compared to that at $150^{\circ} \mathrm{C}$, although it is still significant. After 90 days at $100^{\circ} \mathrm{C}$, approximately $85 \%$ of the TCE remained unreacted. Remember that the reaction rate is limited in these runs by the very low total surface area available for this surface reaction controlled redox reaction and that we used very high starting concentrations of dissolved TCE.

The potential for soil-mineral oxidation of TCE makes hydrous pyrolysis/oxidation a very robust technique; there are a number of chemical reactions that will destroy TCE in soil, provided only that enough heat is supplied to make the reactions run at an acceptable rate.

Thermodynamic data determinations: Geochemical/hydrological modeling of the behavior of chlorinated hydrocarbons at elevated temperatures is severely impacted by the lack of appropriate thermodynamic data. These calculations are required for designing strategies for the thermal remediation of these compounds. The experimental and analytical procedures that we use and the manner in which thermodynamic quantities are calculated from liquid-liquid solubility measurements are described in [Knauss and Copenhaver, 1995b]. By making mutual solubility measurements one can also calculate values for the Henry's Law constant as a function of temperature and pressure.

We have made measurements of the solubility of liquid TCE over the temperature interval $25^{\circ}$ $100^{\circ} \mathrm{C}$ and pressure interval $14.5-7250$ psi. These measurements allow us to determine thermodynamic properties of TCE necessary for modeling its behavior in groundwater systems. Liquid TCE solubility increases with increasing temperature. Based on a regression analyses of our data, we can now calculate TCE solubility at any temperature of interest up to $100^{\circ} \mathrm{C}$. We have also calculated the thermodynamic properties $\Delta \mathrm{G}$ (free energy of solution), $\Delta H$ (enthalpy of solution) and $\triangle S$ (entropy of solution), which are needed to construct hydrologic transport models of TCE behavior in groundwater as a function of temperalure. These values (and their errors) are calculated

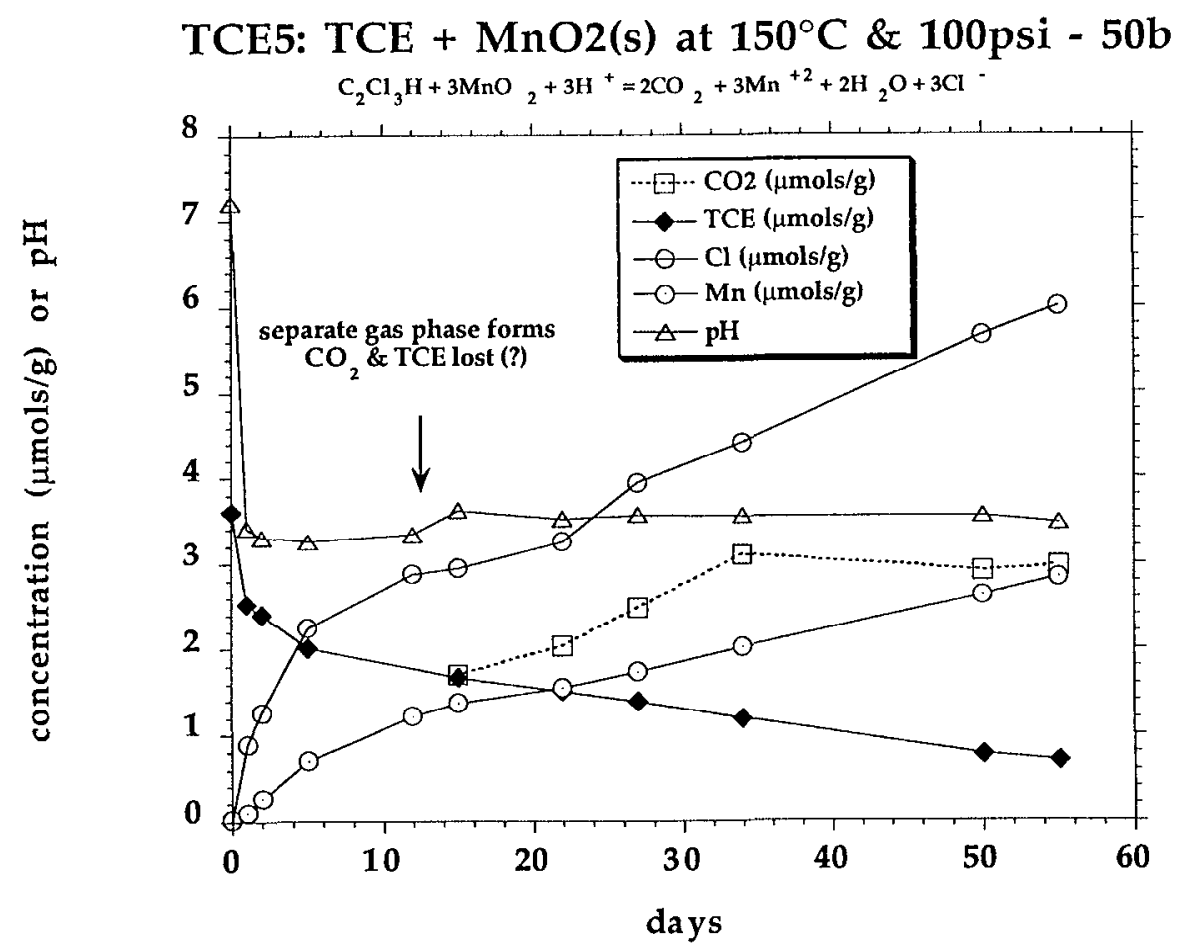

Fig. 10: Oxidation of dissolved TCE by solid $\mathrm{MnO}_{2}$ at $150^{\circ} \mathrm{C}$ and $100 \mathrm{psi}$. 
by regression, as shown in Fig. 11 .

\section{Field Implementation}

The oxidation of TCE at steam temperatures is extremely rapid (several days or less) if sufficient oxygen is present (Fig. 8). This phenomenon of "hydrous pyrolysis" may be utilized to destroy TCE, DCE, (and probably other compounds not yet tested) in situ. This result can permit huge cost savings, because the operation of treatment facilities is the most expensive part of environmental restoration at LLNL (average $\$ 1 \mathrm{M} /$ year/facility, of which about half is a straight facility operating cost). Hydrous pyrolysis may also permit treatment of tritium-contaminated sites where groundwater cannot be extracted. Because the treatment is simple, it can be applied to large volumes of earth. The energy cost will probably be the limiting factor. However, at a cost of $\$ 1.50$ /cubic yard heated to the boiling point by steam, it is feasible to consider treating the entire 4.5 million cubic yards of soil at LLNL containing groundwater with more than $100 \mathrm{ppb}$ of total chlorinated solvents.

A huff-and-puff treatment would be utilized as the prime treatment method using the following steps (Fig. 12).

1. Steam mixed with a small amount of oxygen (approximately $100 \mathrm{ppm}$ ) is injected into a permeable zone to build a small steam zone. Approximately $400 \mathrm{lbs}$ of steam are required for each cubic yard of soil.

2. Steam injection is halted, and groundwater returns to the heated zone. About $1 / 15$ th of the water in the heated zone is condensed from the steam. Oxygen present in the steam dissolves in the water as the steam condenses.

3. Heat retained by the soil heats the returning groundwater (and entrained TCE) to nearly $100^{\circ} \mathrm{C}$. TCE is oxidized by the oxygen contained in the water.

4. Steam is reinjected, building a larger heated zone and repeating the oxidation process. The process is repeated until the steam zone growth is limited by heat loss to the edges.

\section{TCES-1: van't Hoff Plot}

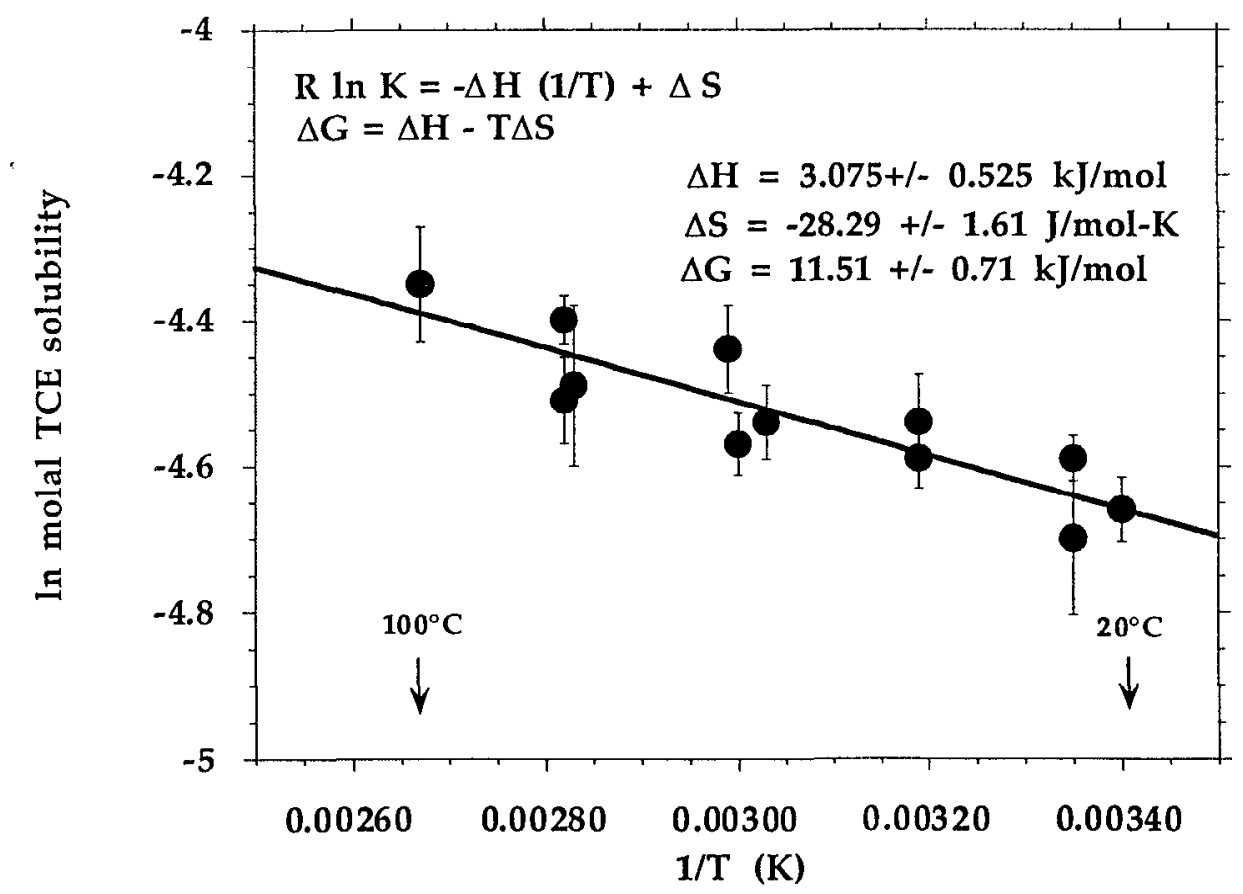

Fig. 11: The van't Hoff plot of TCE solubility and calculated thermodynamic quantities. 
The cyclic steaming ensures that any water displaced by the steam injection only moves a few meters before being pulled back through the hot zone and cleaned. Oxygen gas is used instead of air to increase the rate of oxidation while keeping injection temperatures high; the addition of inert gas reduces the partial pressure of steam in the system, and hence it's boiling point. Direct replacement of oxygen by air would reduce the oxygen concentration by a factor of five, and hence the rate of oxidation would be reduced.

If there is no biofilter downstream, as is envisioned for this project, water must be pumped to make room for the injected water (steam) so that the plume is not displaced. A robust direct-drive down-hole pump such as those used in the oil industry could be used to extract groundwater while steam is simultaneously injected. The dynamic underground stripping experience shows that some condensed water will always be recoverable from even a steam injection well.

The time required to process TCE by this technique can be estimated from our existing data. If we make the assumption that the reaction rate order with respect to oxygen is one, then from our

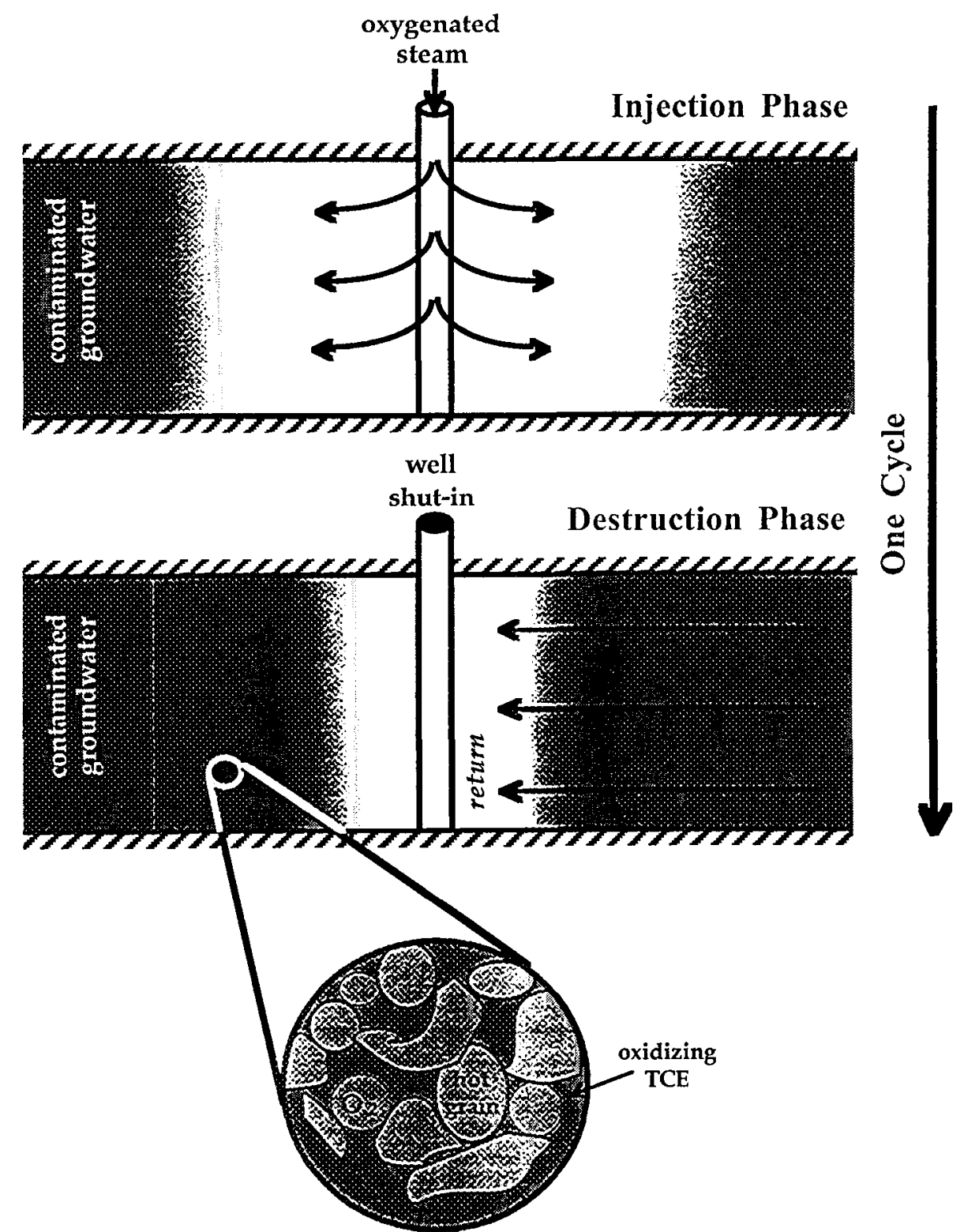

Fig. 12. Schematic description of field application of in situ hydrous pyrolysis. Steam and oxygen are injected together for a brief period; when injection is stopped, water returns to heated area. Successive injections increase heated zone size until limit for well is reached (determined by heat loss to sides and rate of steam injection). 
Arrhenius relationship we can calculate an approximate field of rates vs temperature and oxygen content (Fig. 13). At typical steam-zone-collapse pressures of 3-4 bar, approximately 100 ppm of oxygen is soluble in water (note that nitrogen is not present as in air, which enhances the oxygen solubility). Approximately 10 days would be required to destroy saturated TCE in water under these conditions. Note that the extrapolation to low temperatures indicates that the reaction would take 300 years under ambient conditions, confirming the field observation that oxidation of chlorinated solvents is not a significant ongoing natural process.

The secondary process benefits are:

1. Current oxygen levels in groundwater are greater than the stoichiometric amount of oxygen required to destroy existing TCE. Although the process would be slow (due to lower oxygen fugacity), TCE can be expected to oxidize in heated areas even if no oxygen is added.

2. Manganese oxide minerals ubiquitously present in the LLNL subsurface have also been shown to oxidize TCE.

3. Heating increases diffusion, dissolution, and transport, speeding the removal of TCE from less permeable sediments.

Many remediation processes are limited by the access of the reactants to the contaminant. Mass-transfer limitations are the bane of remediation efforts in low-permeability media. The heating produced by steam-based hydrous pyrolysis will utilize a number of mechanisms to overcome mass-transfer limits and speed up the natural degradation of TCE to non-toxic products:

- Increased volatility of contaminants (Fig. 14): Rapid mass transfer of volatilized contaminants into the steam zone greatly increases access to contaminants that are in less permeable sediments. All of the DNAPI, contaminants of concern to the DOE will boil at steam temperatures.

- Lower viscosity of water and contaminants (Fig. 15): the reduced viscosity of water and DNAPL components leads to more rapid mobilization of liquids from tight sediments, provided the sediments are heated by steam on both sides. When only one side is heated, vapor mobility would be the principal enhanced transport factor.

- Rapid diffusion and evaporation (Fig. 16): The increase in diffusion rates which occurs

\section{Estimated Time To Degrade TCE to MCL (Log Scale)}

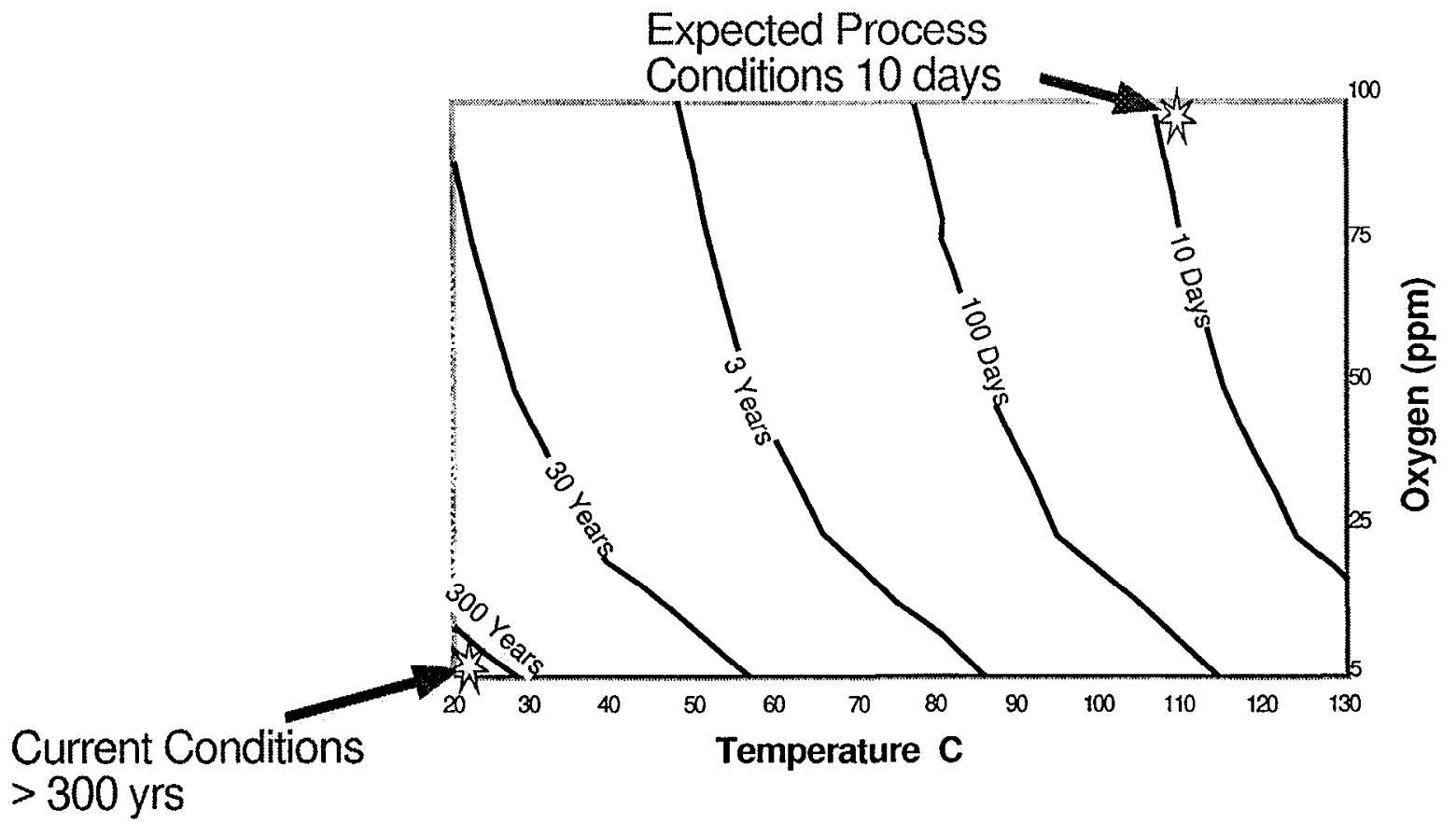

Fig. 13. Using steam heating with oxygen enrichment, the time to degrade TCE to MCL is small 
at high temperatures is a substantial factor in "reversing" the movement of contaminants into tight sediments. Although many years have often elapsed since spills occurred, allowing much diffusion into impermeable sediments, the greater-then-five-times increase in diffusivity at $100^{\circ} \mathrm{C}$ makes a significant contribution toward rapidly removing those sheltered contaminants.

- Boiling of the formation: the rapid formation of vapor when overall formation pressure drops (Fig. 17) can mobilize fine particles and open permeability pathways. Repeated huff-and-puff cycling is expected to optimize this effect.

Process control: Process monitoring would be used to measure the extent of the steam zone (as in dynamic stripping), and the oxygen/TCE content of the groundwater. The process would be optimized to allow the maximum rate of steam injection while still obtaining full TCE destruction. I.I,NL's down-hole sensors would be excellent for this type of process control, by simultaneously measuring the temperature, oxygen content, and TCE content of water that was undergoing treatment underground. Addition of oxygen could also be minimized, both to keep down costs and to avoid any air-stripping of contaminant into the vadose zone. These process control measures should be sufficient to allow (semi)automation of the system. Working with the dynamic underground stripping industrial licensees with oil-field experience should make this a reality; they have extensive experience with automated steam injection systems.

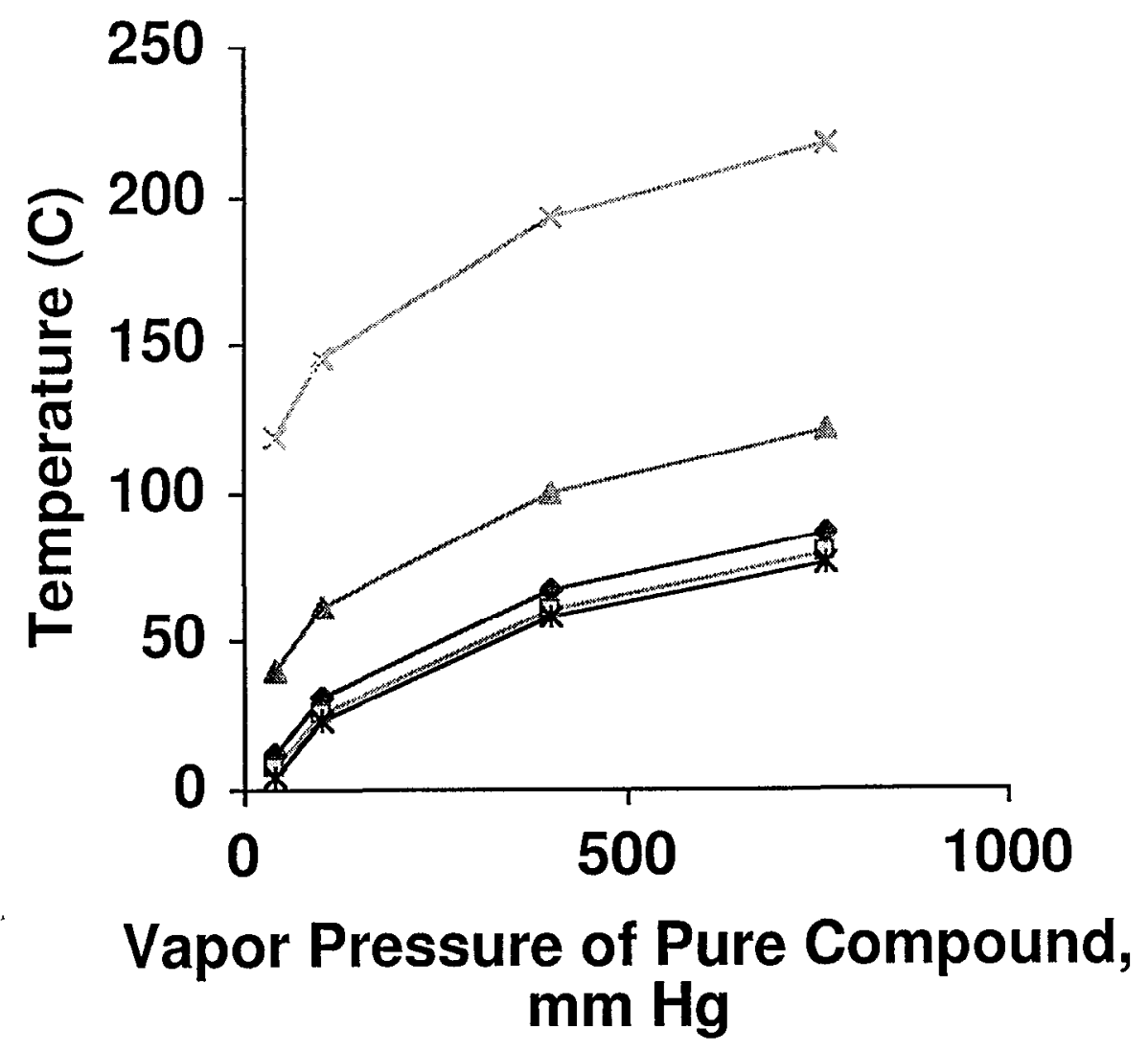

$-\bullet$ TCE $\rightarrow-$ Benzene $\rightarrow$ - PCE $\rightarrow \leftarrow$ Naphthalene $\rightarrow$-Carbon Tet

Fig. 14: The vapor pressure of many contaminant compounds often exceed $760 \mathrm{~mm}$ at steam temperatures. Even less volatile compounds like napthalene have very significant vapor pressures at steam temperatures, facilitating mass transfer in the gas phase. 
Long-term effects: After the system is shut off, it will continue remediating the low-concentration areas around the source for many years. As the warm water migrates, TCE will slowly degrade. Very little oxygen is required. On a weight-for-weight basis, each gram of oxygen in water will destroy three grams of TCE. As heat diffuses into the impermeable zones, it will destroy the TCE trapped in those laycrs. In this respect the heating methods are extremely robust; steam forces its way into the lowest permeable zones, and diffuses into the rest. If steam cannot get into part of the formation, then TCE could not either. Since the TCE is destroyed in place and does not have to be transported back out of the formation, the overall process is more robust than dynamic underground stripping as implemented at the LLNL gasolinc spill area.

Vadose zone effects: The hydrous pyrolysis/oxidation system envisioned, and proposed for the LLNL main site accelerated cleanup (below) is equally effective in the vadose zone and the saturated zone. We have focused on saturated zone issues because there are many vapor extraction techniques that work well in the vadose zone. In remediating a source region, however, it may prove advantageous to treat the entire soil column. If excess oxygen is used in the steam injection cycle, the formation of oxygen bubbles may present a pathway for migration of contaminant back into the vadose zone or serve as a sparging medium. Control of the oxygen content of steam, and it's consumption by the formation, is required.

\section{Visalia Field Test}

Robin L. Newmark, Roger D. Aines, Kevin Knauss, Roald Leif, Marina Chiarappa, Bryant Hudson, Charles Carrigan, Andy Tompson, Jim Richards, and Jane Ferguson conducted a field

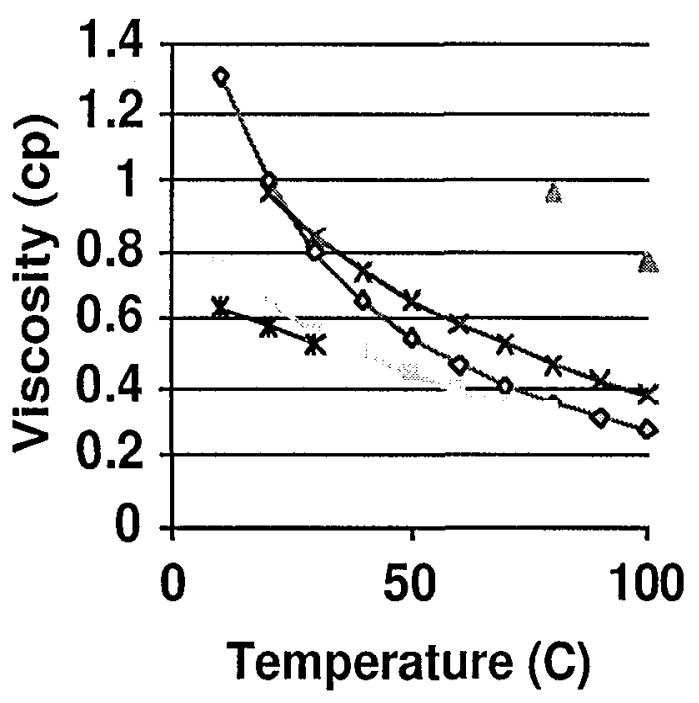

$-\sigma-$ Water $\quad$ Benzene
$\rightarrow-$ Napthal ene $\rightarrow$ - Carbon tet
$\rightarrow-$ TCE

Fig. 15: The viscosity of water and DNAPL contaminants is reduced at steam temperatures, facilitating mixing and increasing diffusion rates.

\section{Aqueous Diffusivity}

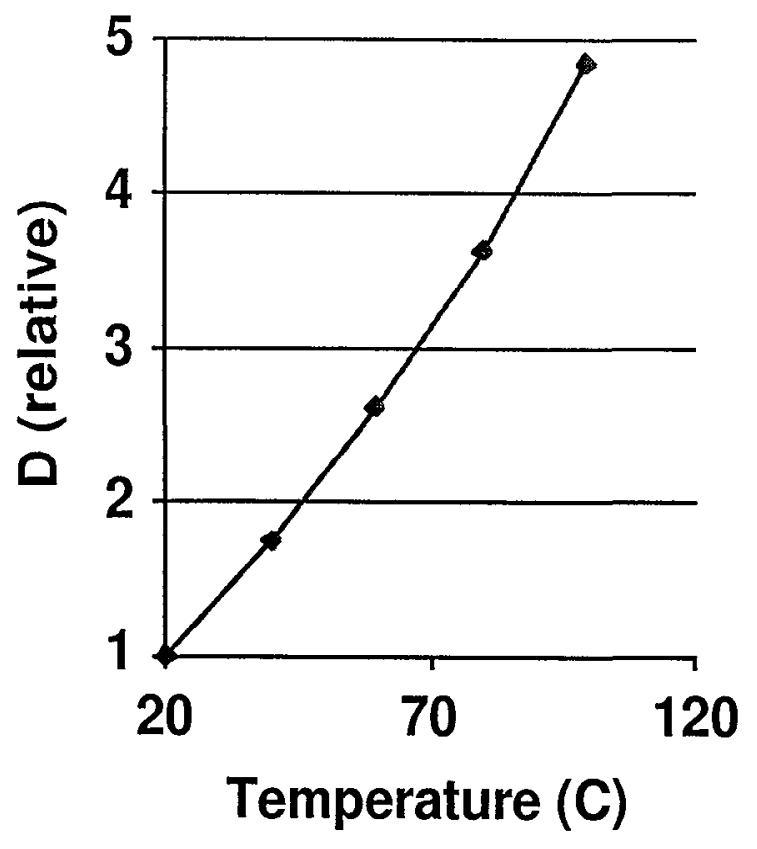

Fig. 16: Increased diffusion at elevated temperature can be estimated from the Stokes-Einstein relation. Diffusion out of tight sediments is much more rapid that was the diffusion inward, partially making up for the frequently long period of time during which contaminants were allowed to migrate into tight sediments. 
test of hydrous pyrolysis/oxidation (HPO) leveraging a commercial application of thermal remediation (Dynamic Underground Stripping (DUS)) at the Visalia Pole Yard (a superfund site) in southern California. This work was a true collaboration, leveraging efforts funded by DOE, LDRD and private industry. The LDRD effort provided the means by which the field test could be conducted; in particular, the development of the analytical systems that were essential for assessing the progress of HPO in situ.

At Visalia, Southern California Edison is applying the DUS thermal remediation method to clean up a large (over 4 acre) site contaminated with pole-treating compounds chemicals (primarily creosote and pentachlorophenol) and an oil-based carrier fluid. This is a full-scale cleanup, during which initial extraction of contaminants will be followed with combined steam/air injection in order to enhance the destruction of residual contaminants by HPO. Laboratory results (funded by Edison) indicated that the contaminants at Visalia would react at similar rates to TCE, which has been the focus of work done for DOE EM 50. The soil conditions are very similar to those at LLNL, the site initially proposed for a field test. Field experimental results from this application are yielding valuable information (1) confirming the destruction of contaminants in soil and groundwater by HPO, (2) validating the predictive models used to design HPO steam injection systems, (3) demonstrating that accurate field measurements of the critical fluid parameters can be obtained using existing monitoring wells (and minimal capital cost) and (4) obtaining a reasonable prediction of the cost and effectiveness of HPO by the close of FY97, working at a commercial scale and with commercial partners.

The goal of our additional study and demonstration in conjunction with Edison has been to obtain early proof of hydrous pyrolysis in the field, and validate our predictive models and monitoring strategies. This demonstration will also provide valuable economic and practicability data obtained on a commercial scale.

Background: Southern California Edison's Visalia Pole Yard site currently contains DNAPL product composed of pole-treating chemicals (primarily creosote and pentachlorophenol) and an

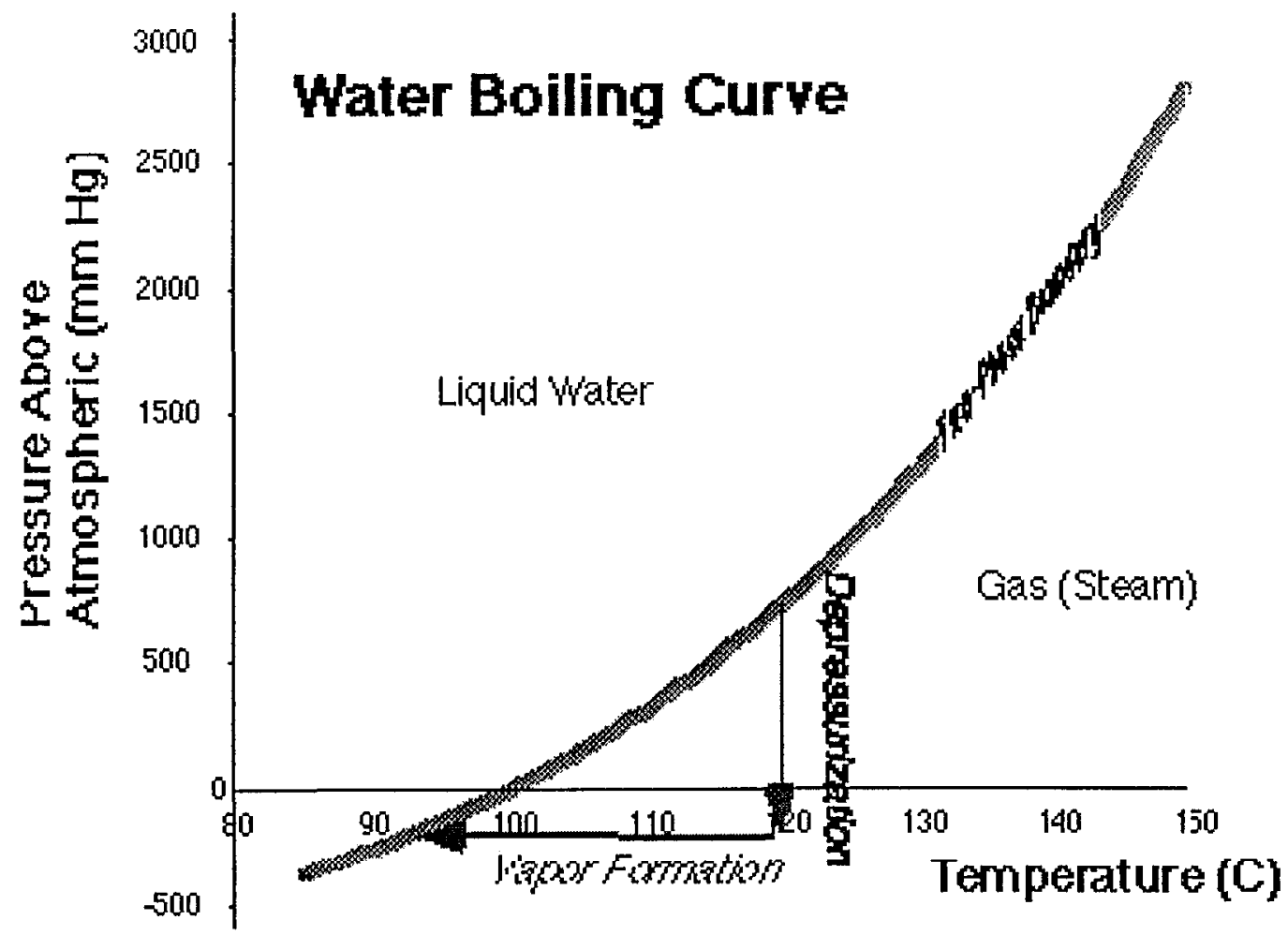

Fig. 17 Boiling curve of water (constrained temperature and pressure where both liquid water and steam can coexist). Effect of reducing the applied pressure on a heated zone is to generate vapor (steam) (shown); effect of cooling a heated region is to draw a vacuum as water condenses. 
oil-based carrier fluid. Bioremediation of the free-organic liquids may be prohibitively slow. Therefore, thermal treatment of the site (such as used in the recent Dynamic Underground Stripping demonstration [Newmark, 1992] is being used for removal of the free product. The overall objectives of the thermal remediation of the Visalia Pole Yard are to remove a substantial portion of the DNAPL contaminant at the site, thereby enhancing the bioremediation of remaining contaminant, and to significantly shorten the time to site closure as well as improving the accuracy of the prediction of time to closure. As part of the final removal process, Southern California Edison will also implement hydrous pyrolysis, an in situ method of destroying organic contaminants using small amounts of supplemental air or oxygen. Their primary need for HPO is destruction of residual pentachlorophenol, which will not readily steam strip.

Because the Visalia site is physically very similar to the recently completed demonstration of thermal remediation at the LLNL gasoline spill site, the physical aspects of the remediation are anticipated to be very similar (the chemical differences in the contaminant were the basis for a laboratory feasibility study). The ability to uniformly heat the LLNL site gave great certainty that this goal can be accomplished at Visalia. Although the site is approximately 2-3 timcs larger, the issues are similar. The LLNL experience also confirmed that the process would be accurately monitored and controlled.

At the Visalia Pole Yard, there is DNAPL contamination in three distinct water-bearing zones (Fig. 18). For the purposes of discussion, we consider the several shallow aquifers as one unit from about 35 to 75 feet below ground surface, and the intermediate aquifer from about 75 to 105 feet below ground surface. The most shallow contamination, above 35 feet in depth, will not be directly targeted by thermal methods (bioremediation is working well enough at this depth). The most sensitive ground water resource is found in the deep aquifer, below about 120 feet. The thermal remediation system must remove contaminant from the intermediate and shallow aquifers, without disturbing the deep aquifer.

Edison currently plans to remove as much free-product creosote and oil as possible by steam injection/vacuum extraction. Fig. 19 shows the injection/extraction layout and the approximate contours of free-product contamination in the three permeable levels (the upper most level is not being treated). They estimate that as much as 20 railroad tank-cars of creosote may be present in the soil. Following this step, after approximately six to nine months of operations, they will begin

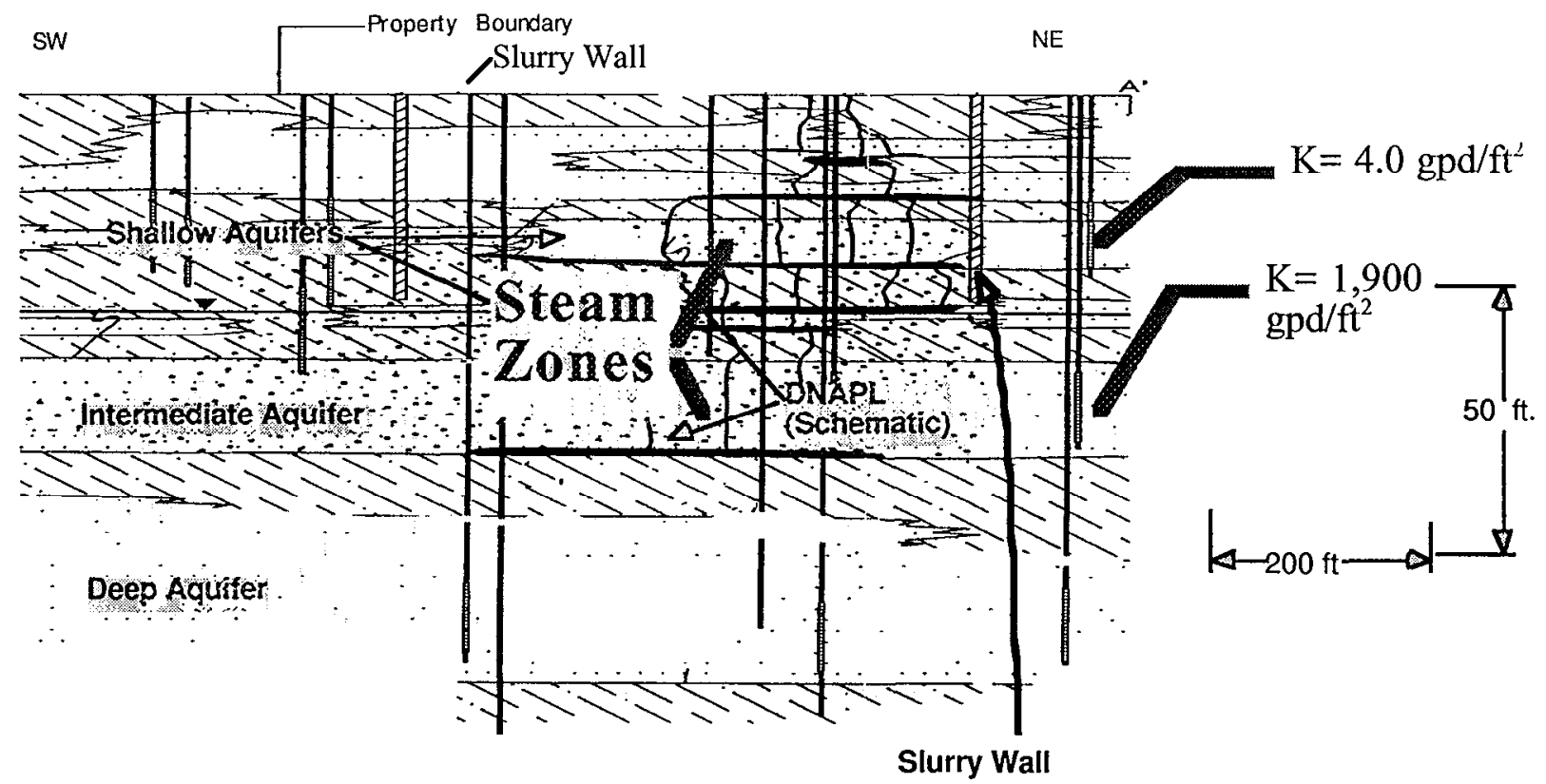

Fig. 18: Cross section (approximately northeast-southwest) through the Visalia site, showing the current status of DNAPL contaminant and approximate lithology. Depth to water is about $60 \mathrm{ft}$ today (the shallow aquifer is unsaturated). Drinking water is produced from the uncontaminated deep aquifer. 
injecting air with the steam to enhance hydrous pyrolysis of the remaining contaminant. They have funded an extensive laboratory study of hydrous pyrolysis of their contaminant suite (described below) and all of the contaminants have been observed to be degradable by HPO.

The goal of our additional study and demonstration in conjunction with Edison is to obtain early proof of hydrous pyrolysis in the ficld, and validate our predictive models and monitoring strategies. We will combine this data with Edison's economic and practicability data to achieve Gate 6 status for HPO.

Field analysis: In order to evaluate the progress of the chemical destruction in situ, we developed field methods for sampling and analyzing hot water for contaminants, intermediates and products of reaction. Since HPO is largely an aqueous-phase reaction, it is essential to capture the fluid chemistry for evaluation. At elevated temperatures, many of the key constituents are sufficiently volatile that traditional sampling techniques are not suitable. We developed two high temperature packer and pump systems capable of delivering a pressurized, isolated fluid stream to the surface, where in-line analysis can be performed. In particular, in-line measurement of dissolved oxygen was important, as the consumption of oxygen through HPO is a crucial operational parameter; if there is insufficient oxygen, destruction will cease. The pressure and temperature conditions in which we desire oxygen measurements exceed the normal operating limitations of most commercially available sensors. We tested a suite of oxygen sensors, including an experimental fiber optic sensor developed in collaboration between LLNL and Tufts University, to determine

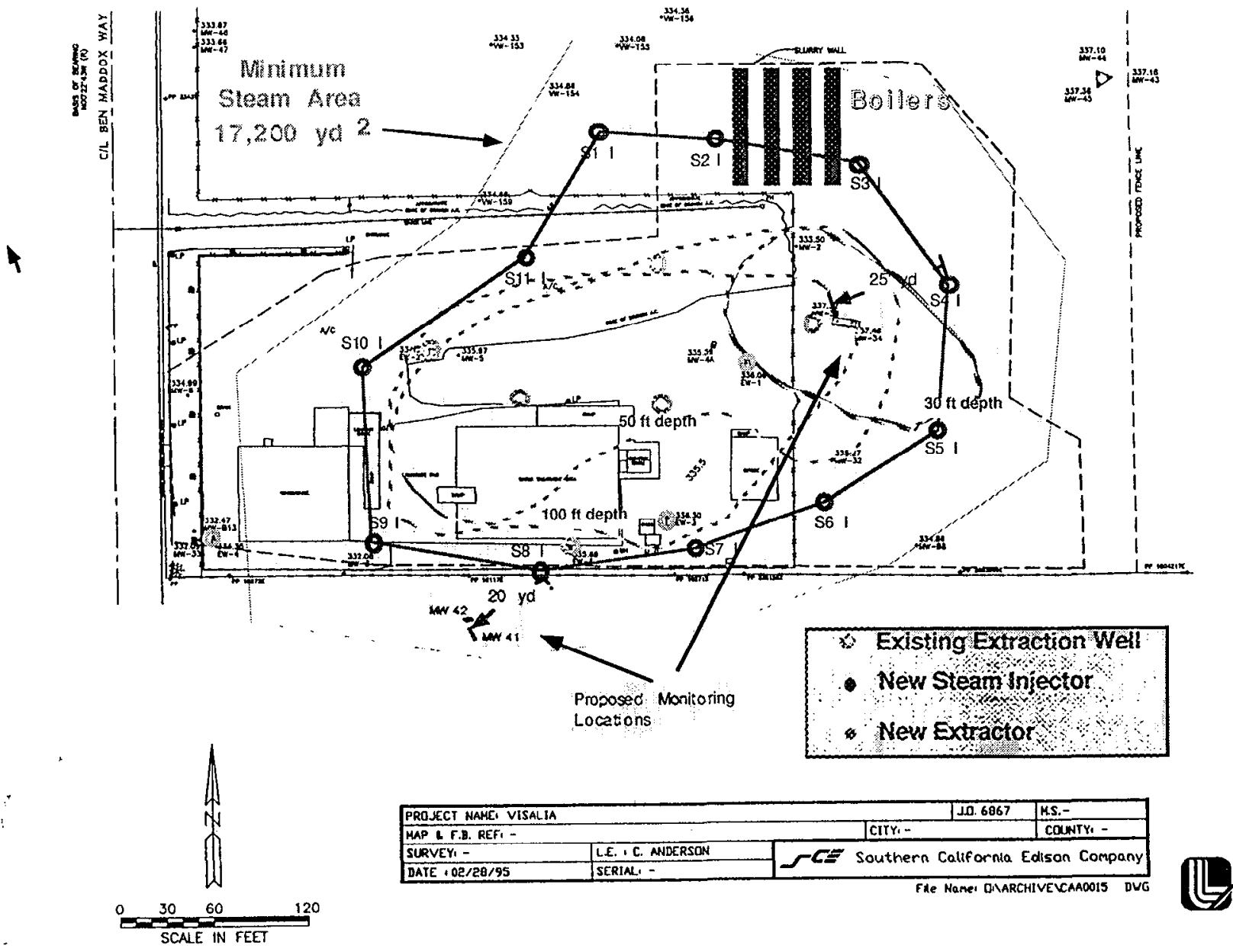

Approximate locations for steam injector wells and extraction wells Visalia Pole Yard, Southern Calif ornia Edison Co.

Fig. 19: Site map of the Visalia Pole Yard, showing the well locations. 
their relative applicability for usc in HPO evaluation, and their potential for in situ use. Essential in-line analytical diagnostics included gas chromatography for organic constituents and mass spectrometry for gaseous species. For use at Visalia, an additional challenge posed was to protect the existing plastic monitoring wells from temperature-induced collapse. We modified the packer systems to provide circulating cooling fluids to both protect these wells and to permit our sampling them during steam injection. These systems have performed successfully during the first several months of steam operations, both protecting the wells and providing valuable fluid samples. In the course of doing this, we have demonstrated that we can monitor in existing wells (a large cost savings!).

Since the addition of air or oxygen to the contaminated region is a critical aspect of HPO, we used noble gas tracers to track the movement of the steam (and subsequent condensation to liquid water) and other gases initially present in the steam. This has become particularly important as the HPO testing was being conducted in parallel with a full-field steam mobilization; the tracers are utilized to identify those fluids directly derived from the injectate of interest, as opposed to native fluids or condensate from injection wells elsewhere in the field The tracers were used to follow the injected steam/water/oxygen pattern from one injection well, measure how well mixing occurs, how oxygen is consumed and carbon dioxide produced/transported, how the intermediate HPO destruction products correlate with temperature and oxygen, how well the existing ERT system can monitor the steam/temperature/mixing phenomena, and the overall isotopic content of the extracted carbon forms with regard to both carbon-14 and carbon-13. The combination of accurate fluid sampling and tracking of the injected fluids allowed us to reliably diagnose the amount of in situ destruction occurring in the treated region.

The subsurface conditions are complex, involving multiple phases and phase changes combined with mass and heat transport. We used advanced numerical modeling in order to interpret the results of the experiments. These calculations are based on a non-isothermal, unsaturated zone transport code (NUFT) which includes individual gas properties in the multiphase system. Model calculations give tracer concentrations in time and space that are directly comparable to measurements. The experimental results show remarkably close agreement with the simulations. The high degree of confidence we have gained from this work has lead us to utilize these predictive tools in designing the experimental protocols.

A key question in the design of in situ HPO systems is the degree to which the heat, oxygen and contaminant can be mixed. Initial concerns focused on whether or not piston-like flow conditions would dominate, which would reduce the mixing zones crucial to the success of HPO as an in situ remediation technique. The first tracer experiment was designed to address hydrology issues of mixing and dispersion. Large dispersive mixing of the tracers was observed. This is in good agreement with calculations when realistic random permeability field realizations are used in the subsurface model. Calculations using uniform media underestimate dispersive mixing by more than a factor of ten, in clear contrast to field measurements. Strong dispersive mixing of oxygen, contaminant and hot water is a critical aspect in promoting hydrous pyrolysis/oxidation. In short, the results of this first experiment yielded excellent results favoring the success of HPO in the field.

Evidence of the progress of HPO comes from a number of sources, including the disappearance of dissolved oxygen (consumed through the HPO reactions), the appearance of oxidized intermediates, the production of carbon dioxide (a final product of HPO), and the provenance of the carbon it contains (indicating the destruction of contaminant rather than other carbon sources). The second experiment involved supplementing the steam with air injection, increasing the dissolved oxygen available for HPO. Positive evidence of HPO was found on all counts (see below). A surprising finding was evidence of HPO occurring during and after the first, hydrology-focused experiment, which did not include the supplemental air (and thus oxygen).

Dissolved oxygen decreases in fluids after steam collapse, indicating the consumption of oxygen during HPO. Our measurements of oxidized intermediates in the Edison extraction wells increased dramatically when Edison shut off the steam in the western wells in mid July. Simple oxidates included in the EPA 8270 method (benzoic acid, phenol, methyl phenols) make up almost 
$1 \%$ of the extracted organics sampled post collapsc. These intermediates have a short lifetime, so a $1 \%$ concentration represents a large, but as yet unquantified, destruction rate.

Carbon dioxide, the final product of the HPO reaction, was measured in the vapor phase present in both the injection well and in the primary extraction well used for LLNL's testing. This steam-rich vapor consists of a steam-carbon-dioxide mixture with small amounts of air. The extraction well also contains large amounts of oxidized intermediate products. Carbon-14 analyses to confirm the origin of the carbon dioxide gas are currently being performed on the accelerator. These analyses will allow us to quantify how much of the carbon dioxide in the intermediate aquifer is due to the hydrous pyrolysis/oxidation of the contaminant. Approximately $0.5 \%$ of the vapor stream extracted by Edison, at a rate of $2500 \mathrm{scfm}$ (or approximately 250,000 Ibs air per day) has been carbon dioxide. This amount is far larger than present in the atmosphere (about $330 \mathrm{ppm}$ ) or initially dissolved in the groundwater. All bicarbonate in the ground water, if converted to carbon dioxide, would amount to $150 \mathrm{ppm}$ of carbon dioxide; Edison pumps about 3 million pounds of water per day. Our initial results from vapor extracted from individual wells used in our tests indicates that a sizable fraction $(30-40 \%)$ of the carbon dioxide recovered from the reaction zone contains "dead" carbon, indicating it is derived from the contaminant, while bicarbonate in the water was nearly unchanged from baseline values, indicating that it does not equilibrate with the carbon dioxide being generated by HPO.

Edison achieved full initial heating of the Visalia site by the end of July, 1997 (over 500,000 cubic yards at a temperature of $100 \mathrm{C}$ or above). Over a 6.5 week period between late June and early August, approximately 300,000 lbs of contaminant was either removed or destroyed; the prethermal treatment removal rate had been $10 \mathrm{lb} /$ week. About 20,000 gallons of free-product liquid had been removed during this period, which is currently stored in temporary tanks on site. Vapor and water streams continue to be saturated with product. Continued destruction by HPO is indicated by the high levels of carbon dioxide removed through vapor extraction. Destruction levels are currently being calculated. Edison has now adopted a huff and puff mode of operation, where the steam is stopped for several days to a week while extraction continues. Maximum contaminant removal is obtained during this steam-off period as the formation fluids flash to steam under the applied vacuum of about $1 / 4$ atmosphere $(2500 \mathrm{scfm})$. We will continue to monitor the progress of HPO throughout the field. 


\section{In Situ Microbial Filters}

\section{Concept}

In situ microbial filters employ a resting-state bioaugmentation technique to remediate contaminated ground water. In this method, naturally-occurring bacteria are grown in surface bioreactors, separated from their growth medium (resting-state), resuspended in an aqueous solution without the growth substrate, and then injected into the subsurface (bioaugmentation). The selected bacteria are nonpathogenic and pose no danger to human health. A significant fraction of the injected bacteria attaches to the aquifer media to create a fixed-bed in situ biofilter.

Fluid injection to establish an in situ biofilter occurs over a short period of time. After cell injection is terminated, the natural groundwater flow regime re-establishes itself. However, this flow regime can be amplified by the up-grading steam injection in large quantities, or by nearby fluid extraction down-gradient from the biofilter. Flowing ground water transports dissolved contaminants to the biofilter where they are biodegraded. The rate of biodegradation in the engineered biofilter is designed to balance the contaminant transport rate so that clean ground water exits the biofilter. Thus, the plume is prevented from further migration and is severed from its source region by this strategy.

\section{A Proof-of-Concept Field Experiment}

A recent field test at the Chico Municipal Airport [Duba et al., 1996] demonstrated that an in situ biofilter using resting-state cells can effectively remediate ground water contaminated with chlorinated solvents. A purc strain methanotrophic bacteria was suspended in ground water and injected (at $4 \mathrm{~L} \mathrm{~min}^{-1}$ ) into an aquifer through a single well at a depth of about $28 \mathrm{~m}$. The injected ground water was devoid of growth substrates and cosubstrates but did contain a tracer. Baseline studies at the injection location found the ground water to be contaminated with $425 \pm 50 \mathrm{ppb}$ of trichloroethene (TCE). Approximately 50\% of the injected bacteria attached to the soil, forming an in situ, fixed-bed, quasi-spherical bioreactor with an average radius of about $1.2 \mathrm{~m}$ and an attached population density of approximately $500 \mathrm{M}$ cells per gram of aquifer material. Contaminated ground water was subsequently withdrawn through the biofilter by extracting water through the injection well at a rate of 4 to $2 \mathrm{~L} \mathrm{~min}^{-1}$. Results show that $98 \%$ of the TCE was biodegraded for

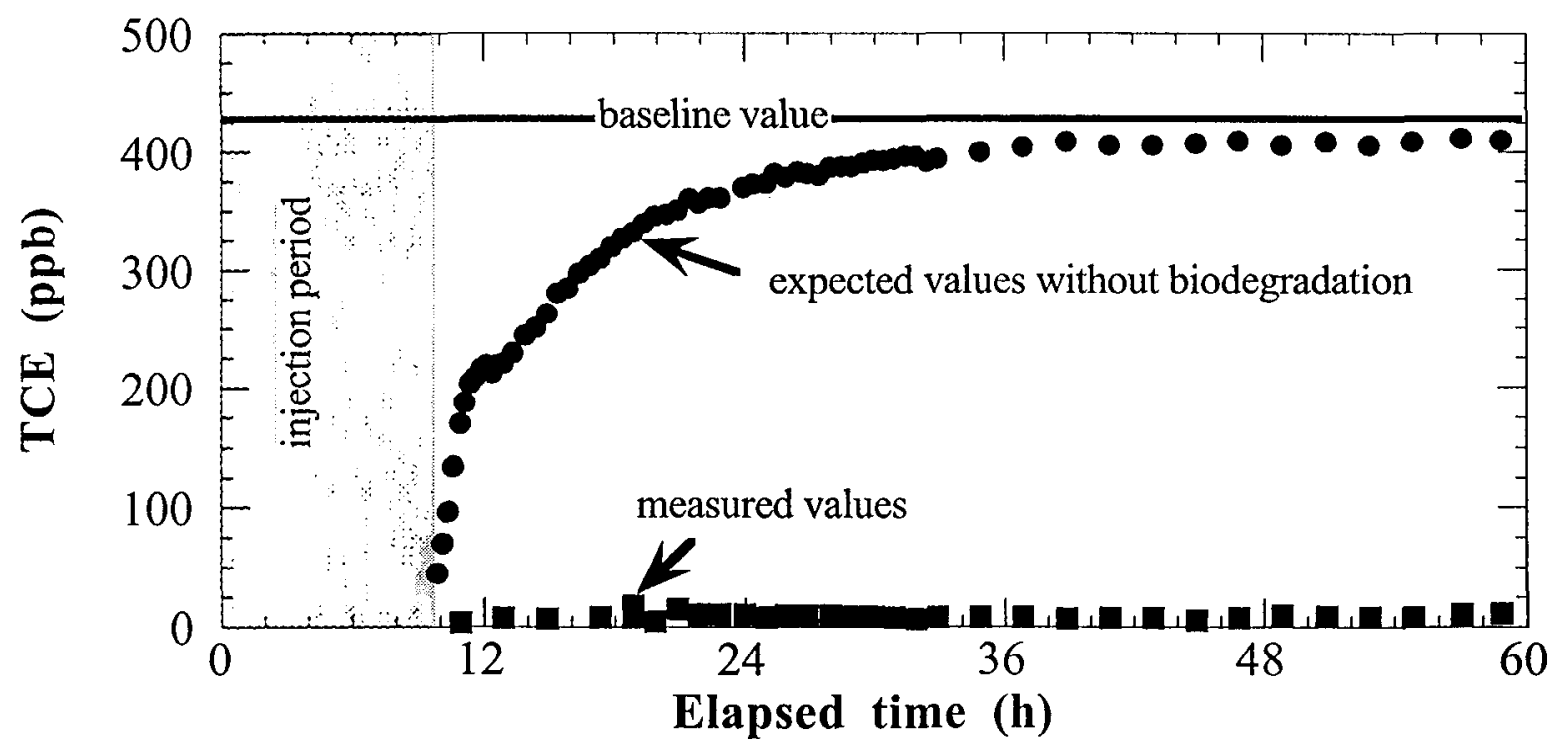

Fig. 20: An emplaced biofilter reduced TCE concentrations by about $98 \%$ during the first 60 hours of operation. TCE concentrations expected without biodegradation were calculated from recovery of an injected tracer during the extraction phase. 
the first 50 hours of ground water withdrawal (Fig. 20). In the ensuing days, TCE concentrations at the withdrawal well gradually increased with biodegradation persisting until the experiment was terminated 40 days after initiation. This field test conclusively demonstrated that an in situ biofilter can (1) successfully be emplaced into the subsurface, (2) decrease substantial contaminant concentrations to ncar regulatory limits, and (3) sustain degradation over cxtended periods of time.

\section{LLNL Site Approach}

In situ microbial filters can be employed at the LLNL site in a synergistic fashion in conjunction with steam injection and pump-and-treat operations to remediate ground water contaminated with chlorinated solvents. The primary area of application is the eastern part of the site where most of the contaminant sources are located. The main concept calls for emplacing in situ biofilters within the appropriate hydrostratigraphic units (HSUs) down-gradient from contaminant sources and near the 100 to $50 \mathrm{ppb}$ contaminant concentration contour interval. Natural groundwater flow, augmented by steam injection up-gradient from the biofilter and pumpand-treat extraction down-gradient from the biofilter, will bring contaminants through the treatment zone where they will be degraded to harmless compounds such as aqueous $\mathrm{CO}_{2}$ and chloride ions before they exit. Important aspects of the biofilter deployment are site suitability, contaminant targeting, biofilter design, commercial cell production, and delivery systems. Each of these aspects is discussed in the following paragraphs.

Site suitability: Criteria to evaluate the suitability of a particular site can be categorized into three groups: soil characteristics, ground-water chemistry, and contaminant characteristics. Soil characteristics control site suitability mainly through fluid transport attributes. The resting-state biofilter process requires that bacteria be injected into the subsurface and that cells be transported moderate distances to established the fixed-bed filter. This requires pore geometries that permit the cells to pass through them. M. trichosporium OB3b is rod shaped with dimensions on the order of $1 \mu \mathrm{m}$ long and $0.5 \mu \mathrm{m}$ in diameter. Experience in the laboratory with manufactured porous plates suggests that pore throats greater than about $20 \mu \mathrm{m}$ are sufficient to permit effective cell transport; pore throat sizes less than this have been observed to result in a build-up of cells and eventual clogging. The role of suspended cell concentrations in this phenomena is not yet clear, but work to date used concentrations of $1 \mathrm{G}$ cells $/ \mathrm{mL}$ or less, which are the maximum concentrations that would be used in field injections. Pore throat sizes of $20 \mu \mathrm{m}$ or more can be expected in contaminant-bearing HSUs at the LLNL site, although this issue will be examined specifically during the first six months of field testing.

Ground-water chemistry is critical because each bacterium has a limited range of conditions in which it can maintain its metabolic capabilities. M. trichosporium $\mathrm{OB} 3 \mathrm{~b}$ is found naturally in brackish to fresh aqueous environments where the $\mathrm{pH}$ is about $7.0 \pm 0.8$. This embraces a wide range of plumes found in quartz-rich soils. The bacterium tolerates a temperature range of about $30^{\circ} \mathrm{C} \pm 15^{\circ} \mathrm{C}$. Preliminary measurements suggest that $\mathrm{pH}$ and temperature at the LLNL site are both within these limits. Laboratory tests of contaminant biodegradation characteristics in representative samples of site ground water will better define this parameter.

M. trichosporium $\mathrm{OB} 3 \mathrm{~b}$ is known to catalyze the oxidative degradation of $\mathrm{C}_{1}$ and $\mathrm{C}_{2}$ chlorinated compounds that have at least one $\mathrm{C}-\mathrm{H}$ bond. Of the compounds found at the LLNL site, this includes the various isomers of DCE (dichloroethene), TCE (trichloroethane), various isomers of DCA (dichloroethane), TCA (trichloroethane) and chloroform. It does not include PCE (tetrachloroethene), carbon tetrachloride, or the two Freon compounds found at LLNL. Over half of the existing wells currently have a contaminant suite that can be biodegraded by $M$.

trichosporium; the remaining wells are in locations where in situ hydrous pyrolysis can act. Thus, these compounds can be eliminated by the thermal treatment before they reach the biofilter.

The in situ biodegradation process requires that sufficient oxygen, an electron acceptor, be dissolved in the ground water to oxidize the contaminants. Each contaminant has its own oxygen requirement. Estimates of this requirement for degradable compounds at the LLNL site can be made by assuming each contaminant compound is completely mineralized. The more reduced compounds require greater dissolved oxygen contents. Whether a site has sufficient dissolved 
oxygen depends on the contaminant suite and their individual concentrations. An upper limit on contaminant concentration is enforced by the oxygen content of ground water in equilibrium with air, which at $20^{\circ} \mathrm{C}$ is about nine ppm. For DCA, the most reduced biodegradable compound at the LLNL site, this upper limit is about $11 \mathrm{ppm}$; for TCE, the most abundant degradable compound at the LLNL site, the upper concentration limit is about $25 \mathrm{ppm}$. However, these limits are only approximate since there is also a poorly defined oxygen requirement for minimal cellular activity in the resting-state. In addition, it is not known if the contaminants are completely mineralized under all conditions. If the reaction terminates at intermediate products, then the demand for dissolved oxygen is less. Nevertheless, these upper limits are all considerably lower than biofilter design requirements in the integrated system proposed for the LLNL site (about $100 \mathrm{ppb}$ total degradable compounds). Preliminary measurements of greater than $4 \mathrm{ppm}$ dissolved oxygen suggest that this will not be a limitation.

A series of laboratory and field tests revealed that the selected bacterial species effectively degrades trichloroethene (TCE) in situ groundwater and under in situ conditions. In addition, it was demonstrated that the bacteria effectively attach to the subsurface geologic media - as would be predicted from previous experience. An in-well treatability study indicated that the bacteria initially degrade $>99 \%$ of the contaminant, to concentrations less than MCI. The duration of this in situ performance is not currently known, but laboratory data indicate that biofilter longevity should be consistent with previous field tests [Duha et al., 1996]. It can be concluded that the in situ microbial filters approach could be used to effectively control the spread of contaminant during steam injection.

Biofilter design: Emplaced in situ biofilters need to be designed such that contaminant concentrations in ground water exiting the filter are below or at target limits for an extended period of time. The resting-state, fixed-bed, biofilter approach reduces design of the field application to chemical reactor engineering. Four basic sets of laboratory-measured parameters govern biofilter design for field application: contaminant residence time, biofilter degradation capacity, enzyme longevity, and attached bacterial population.

Contaminant residence time in the biofilter is the time that contaminated ground water needs to remain in contact with attached bacteria for the dissolved contaminants to be degraded to desired levels. Contaminants are transported through a filter at rates controlled by the groundwater velocity. They are degraded at rates controlled by both the intrinsic biodegradation rates and the attached bacterial population density. These competing rates must be balanced through a sufficient residence time in the biofilter to achieve biodegradation to regulatory levels. Biofilter length (or thickness) along the direction of flow, established at the time of cell injection, provides the greatest degree of control of residence time. These four sets of parameters, groundwater velocity, intrinsic degradation rates, attached population, and filter length, determine the contaminant residence time and form the basis for engineered applications. Existing equations that have been shown to adequately describe the process have been combined in a computer simulator for design purposes.

Filter degradation capacity is the maximum mass of contaminants that can be biodegraded by a fixed attached bacterial population. The in situ microbial filter concept is to inject bacteria into the subsurface in the resting-state. A significant fraction of these microbes attaches to the subsurface media. The attached population does not increase in number, unless reinoculation occurs, because there are no growth substrates in the system. The attached bacteria serve only as repositories of key intracellular biochemicals which catalyze, as well as participate in, the biodegradation reaction. The biodegradation reaction gradually either consumes or inactivates these intracellular biochemicals during the reaction. A given attached cell population contains a fixed amount of these compounds because they can not be regenerated in the absence of a growth substrate. Therefore, each cell and the attached population as a whole can degrade only a certain mass of contaminants before one or all of these intracellular biochemicals are completely exhausted, thereby throttling the reaction. These parameters have been measured in a series of scaled laboratory experiments to confirm a constitutive mathematical model for the process. Intrinsic values for TCE are about 0.25 $\mathrm{g}$ TCE ( $\mathrm{g}$ cell $)^{-1}$. The model permits engineering design of the appropriate population density and filter width to achieved desired performance over an extended period of time. 
The absence of carbon and energy sources in the in situ microbial filter approach implies that eventually the attached bacteria will become metabolically inactive. This inactivation is independent of any contaminant biodegradation reaction and is simply a response to the population starving. At some point the cells either lyse and release their contents to the subsurface environment or, in the case of $M$. trichosporium OB3b, the cells sporulate and suspend metabolic activity until more favorable conditions occur. The biofilter will fail to perform at this stage and population replenishment will be required for its re-establishment. As mentioned above, early supporting work will investigate the disposition and availability of cell attachment sites during the biofilter establishment/replenishment cycle.

The frequency of filter replenishment is a key economic variable. The period of time cells maintain their capability of degrading target contaminants while they are in the resting-state, in the absence of degradation capacity limitations, is enzyme longevity. $M$. trichosporium OB3b can be cultured so that it will stay metabolically active in the resting-state for time periods on the order of months. This is a significant advance since field biostimulation experiments typically report loss of cell activity for time scales on the order of several hours. This advance has been achieved by careful maintenance of key metal concentrations in the growth medium for the duration of the bacterial growth period. The ability to control growth medium chemistry and, consequently, the intracellular biochemical characteristics, is a marked advantage of the bioaugmentation approach.

The population density of attached cells controls both the contaminant residence time in the biofilter and the biofilter degradation capacity. Predictable remediation results require the ability to predict the geometry of the biofilter and the distribution of attached cell population densities within it. Predictive capabilities are necessary for the cell injection process when the biofilter is established as well as for the subsequent contaminant degradation period. The attached cell population will not increase once the in situ biofilter has been established because there is neither an introduced nor natural carbon or energy source for cell division. However, the attached cell population will decrease because groundwater flow causes cells to detach and entrain in the moving water.

Laboratory experiments demonstrate that there is a maximum attached population for a given ionic strength. This maximum attached cell population reaches a minimum at low ionic strengths and a maximum at high ionic strengths; these extreme form two plateaus separated by a transition region. In addition, it appears that there are a limited number of sites available for attachment for any given condition; once these are filled, any further net attachment is terminated. It should be noted that even at high attached populations the cells cover less than $10 \%$ of the surface area of the solid medium.

Coupling with hydrous pyrolysis: Hydrous pyrolysis and in situ microbial filters can be implemented to form an integrated treatment system (Fig. 5). Ground water at the site has an ambient pore fluid velocity of about $1.5 \mathrm{~cm} / \mathrm{hr}$. Steam injected up-grading of emplaced biofilters will eliminate the contaminant source regions and introduce a net flux of fluid which will accelerate migration of the contaminant plume. Biofilters designed and placed to intercept and bioremediate this accelerated contaminant transport will take advantage of changes induced in the natural groundwater flow regime. The accelerated flux will reduce overall system costs because the biofilters will have to be sustained over a shorter period of time to remediate the same volume of ground water. 


\section{Process Monitoring}

\section{Introduction}

This project will use advanced in situ microbial filter and in situ thermal treatment technologies to quickly remediate contaminant source areas beneath the LLNL Livermore site. Innovative hydrostratigraphic analyses will identify these source areas as targets for expedited remediation. For most effective implementation, the innovative cleanup techniques require an advanced level of monitoring for process control and performance assessment. In addition, standard sampling and analysis methods are required for regulatory oversight of the contaminated site.

Monitoring and process control efforts will build on experience in monitoring subsurface treatments and processes. During Dynamic Underground Stripping [Newmark, 1992], for example, the rapid response of the monitoring methods provided near-real time information regarding the thermal processes, allowing the operations engineers to effectively control the subsurface system. Initial field demonstrations will be more heavily instrumented to provide a more detailed understanding of the subsurface processes as the overall operational strategy is optimized.

\section{Issues and Implementation}

Steam injection: The main issue with steam injection is knowing the location of steam front(s) over time. As steam is injected into the ground, it preferentially penetrates the more permeable soils. Lateral and vertical growth of the steam-filled zone is largely controlled by the relative permeability of the formation. In order to effectively heat and clean the contaminated HSUs, the shape and extent of the steam-saturated zone must be controlled. For efficient heating, it is essential to know if steam is moving vertically between units or if it is preferentially channeled in one direction. If supplemental $\mathrm{O}_{2}$ is required, introduction of $\mathrm{O}_{2}$ and heat into the subsurface system must be coordinated to achieve optimum contaminant degradation. Temperatures rise in the steamed zones, and saturations decrease during steam injection. A condensate zone precedes the advancing steam front as it propagates and displaces ground water through the formation. Steam is injected under pressure; as it cools, pore pressures at the steam front decrease. These phenomena influence the physical growth and subsequent collapse of the steam-saturated and heated zones as well as the chemical reactions that can take place in and around them.

LLNL's experience in monitoring subsurface steam injection and steam front propagation will support system design. During steam injection, temperatures rise within and adjacent to the steamed zones, and saturation levels decrease. Since soil electrical properties are sensitive to changes in temperature, saturation, and fluid chemistry, electrical techniques are particularly useful for monitoring these processes. Electrical resistance tomography (ERT) can provide near real-time detailed images of heated zones between boreholes during electrical heating or steam injection. High frequency electromagnetic (HFEM) techniques may also be applicable. Self potential (SP) logs may be able to identify zones of injection influence. Borehole induction logs show close correlation with lithostratigraphy, and, by identifying the more permeable gravel zones, can be used to predict steam movement. Geophysical logs are also useful in understanding the physical changes in the field and in interpreting the electrical tomographic images. Tiltmeters provide information about the lateral extent of the steamed zones; these data complement information provided in cross section by ERT imaging. In the Dynamic Underground Stripping Project tiltmeter systems were used to track the growth of the steam front from individual injectors.

Perhaps the most essential information needed for design of the steam system is identification of preferential steam pathways. Hydrostratigraphic data will be the primary source of this information on a local scale. Current groundwater oxygen concentrations will also be useful in assessing the need for oxygen augmentation and in designing systems to introduce oxygen where needed in the subsurface.

Hydrologic testing, probably including hydrophysical logging, will provide valuable information about expected flow rates and directions, but gives little detail regarding the flow paths 
or potential vertical movement. ERT is an excellent predictor of steam flow, indicating both lateral and vertical flow pathways; HFEM imaging may provide similar details. SP surveys and geophysical borehole logging can identify zoncs of injection influcnce. Tiltmeter surveys performed in conjunction with hydrologic testing can determine the lateral extent of individual capture zones in more detail than is commonly possible using monitor wells alone.

During steam injection, system diagnostics are required for safe and effective operations. Information regarding temperature, pressure and flow rates is needed; it is desirable to obtain this information both at the surface and downhole.

Devices are available commercially for measuring temperature, pressure, and flow rates in surface pipe systems. Measuring these parameters in active wells or in the subsurface is more difficult; however, knowing these diagnostic parameters in situ would greatly enhance operational strategy and cleanup system optimization. Additional development may be able to provide downhole systems for measuring part of this information in the subsurface.

Direct temperature measurements in the subsurface require installation of instruments such as thermocouples. The cost of monitoring steam injection using fixed temperature sensors at the necessary level of detail for the entire project is probably prohibitive. Although some level of in situ temperature measurement is necessary to back up and validate other measurement systems, several other methods are available to obtain information about steam front movement. Since the objective is to heat the ground in the presence of $\mathrm{O}_{2}$, temperature sensors combined with $\mathrm{O}_{2}$ sensors would provide the best type of data to monitor hydrous pyrolysis. Relatively inexpensive fixed thermocouples can be installed in areas where additional temperature information is desired, and this can be supplemented with temperature logs in selected boreholes. An optical temperature logger can accurately measure temperature profiles in the extreme thermal gradients anticipated, but some developmental work is needed to produce a system optimized for this application. Measuring $\mathrm{O}_{2}$ under the in situ conditions is more problematic. ERT is excellent for monitoring the

movement of steam both laterally and vertically; however, as the surrounding ground heats up, the signal contrast due to the steam decreases, making identification difficult. In this application, ERT or HFEM imaging might prove essential for system design and startup, but less useful during later operational phases at a site. Tiltmeter surveys provide lower resolution maps of the lateral shape of the steam front, but little information regarding the vertical extent. Once the vertical extent of steam penetration is determined using ERT and other methods, tiltmeters are an excellent complement to ERT in steam front control. SP surveys may also identify zones of injection influence, with lower resolution than the tomographic methods.

When injection pressure is released, the steam zone will collapse and the groundwater system will recharge. Crucial monitoring questions revolve around the location and nature of the retreating steam front, including both physics and chemistry. TCE breakdown produces acidic conditions; the transient, locally increased acidity should be naturally buffered by the mineral assemblages commonly found in the subsurface. However, with repeated pulses of steam injection (perhaps through a huff-and-puff implementation scheme), it is possible that this natural buffering may be insufficient, so $\mathrm{pH}$ may be an important parameter as well.

The same techniques used to monitor physical and chemical aspects of the advancing steam front will be applicable to monitor steam zone collapse and ground water recharge.

Microbial filter: The main monitoring issues for in situ microbial filter methods revolve around biofilter emplacement, continuity, longevity, and overall performance. Physical and chemical aspects of performance will both be addressed. Biofilters will be emplaced through injection wells; the relative permeability of various hydrostratigraphic units (HSUs) and the attachment affinity of the microbes in those units will affect the thickness and microbial density of the biofilter zone. Overall biofilter performance diminishes as the microbes die and lyse. The rate at which biofilter performance decreases will depend on the ability of the microbes to retain essential enzymes and biochemicals and the severity of the chemical insult to which they are exposed. The biofilter will lose its ability to degrade contaminants in HSUs in which fewer microbes attach due to permeability or geologic factors, or those units in which contaminant concentrations are greatest. In heterogeneous media, the performance history may show individual step changes rather than a 
steady decrease, reflecting contaminant breakthrough in different zones of the HSU. Chemical and biological measurements down-gradient of the emplaced process zone provide diagnostics for overall biofilter performance.

Knowledge of local hydrostratigraphy is essential to design the biofilter and inoculation scheme. Deep emplacement of the biofilter will be accomplished by injection through wells; the relative permeability of different units and the attachment affinity of the microbes in the host units will control the thickness and microbial density of the biofilter zone. In addition to the existing site characterization, techniques that identify local variations in contaminant concentration, details of the formation permeability or lithology, or preferential flow pathways will assist biofilter design.

Many of the necessary physical property data can be obtained through focused hydrologic testing (including hydrophysical logging) and through electrical methods such as ERT or EM imaging. Self potential (SP) surveys may also indicate bulk hydrologic properties. Fiber optic sensors could provide chemical property data, including essential information regarding chemical gradients or variations in important biological parameters.

Similar measurement issues exist for biofilter emplacement and continuity as for the design aspects. However, further hydrologic testing at this point may not add much additional information to meet this set of needs. Steam injection up-grading of the biofilters will impose a pressure gradient to push potentially warm fluids into the microbial process zone, but the temperature range in which the microbes can exist is relatively small. This will require temperature measurements at strategic locations to protect biofilter integrity.

The main monitoring issues related to in situ biofilter performance are chemical or biological in nature. As the microbes die out, the overall biofilter performance will diminish. The rate at which biofilter performance decreases will depend on the ability of the microbes to retain essential enzymes and the severity of the chemical insult to which they are exposed. The performance history can be conceptualized as a thinning of the biofilter with time; the biofilter will gradually lose its ability to degrade contaminants in HSUs in which fewer microbes attach due to permeability or geologic factors or HSUs in which contaminant concentrations are greatest. In heterogeneous media, the performance history may show individual steps rather than a steady decrease, reflecting contaminant breakthrough in different zones. Overall performance can be monitored by analyzing chemical and biological indicators downstream. In situ measurement is desired. Contaminant concentration measurements will assess degradation performance; chemical indicators for bioactivity, such as $\mathrm{O}_{2}$ and $\mathrm{CO}_{2}$ levels, will also be monitored. 


\section{Contaminant Targeting}

The ACI field site has been characterized with 7 boreholes (six completed in HSU-4 and one in HSU-2) which has enhanced our understanding of the subsurface for the test site and allowed us to refine our subsurface targets for hydrous pyrolysis and biofilter.

The main objective for this phase of the project was to characterize the site to enable the project team to conduct a field test in HSU-4, an possibly in other HSUs if the initial test in HSU-4 is successful. Mapping of HSU-4 portrays a series of braided stream channels in which trend northwest in the area. The known maximum permeable section of sediment (net gravel, sand and silty sand) in the HSU-4 channel is 12 feet. The average channel width in this area is approximately $200 \mathrm{feel}$ al depths ranging from 124-140 feet.

The chemistry of the ground in the channel shows concentrations of TCE ranging from $18 \mathrm{ppb}$ to $1200 \mathrm{ppb}$. The higher concentrations appear to reside in the finer grained channel fill material along the margins of the channel. However, some high values are present in some of the coarser materials.

Hydraulic conductivity values range from $5.9 \times 10^{-8} \mathrm{~cm} / \mathrm{sec}$ in the finer grained materials such as clayey silt to $1.8 \times 10^{-2} \mathrm{~cm} / \mathrm{sec}$ in gravely sand. Values in HSU-4 range from $10^{-6}$ on the channel margins to $10^{-2}$ in the well washed central part of the channel fill. Hydraulic conductivity values in soil stratigraphically in HSU-3 above and HSU-5 below HSU-4 range from $10^{-6}$ through $10^{-8}$ respectively, and could potentially serve as confining layers to vertical steam migration depending on the pressure of steam injection.

In conclusion, the site selected for the ACI field test is favorable for both hydrous pyrolysis and biofilter technologies. This conclusion is based on the analysis of the hydrostratigraphy, contaminant hydrogeology and distribution, lithology, geometry of target units, and depths. Additional drilling and characterization activities are needed to further refine the $3 \mathrm{D}$ understanding of the hydrology, and to monitor the effect of hydrous pyrolysis on the contaminant hydrogeology. Numerous ground water monitoring wells are still needed at the project site in order to monitor the 3D activity. These include monitoring well completions in HSU-2, 3A, 3B, 4, and 5. Analysis of this new data, including stratigraphy, VOC concentrations, and lithology, combined with hydraulic tests in all the HSUs will be necessary for a successful project. In addition to the ground water monitoring wells, a CPT should be used to install a dense network of ERT monitoring holes throughout the area to track steam movement as well as further define the stratigraphy. 


\section{References}

Dolfing, J., and D.B. Janssen, Estimates of Gibbs free energies of formation of chlorinated aliphatic hydrocarbons, Biodegradation, 5, 21-28, 1994.

Duba, A.G., K.J. Jackson, M.C. Jovanovich, R.B. Knapp, N.N. Shah, and R.T. Taylor, TCE remediation using in situ, resting-state bioaugmentation, Environmental Science and Technology, 30, 1982-1989, 1996.

Jackson, K.J., A.K. Burnham, R.L. Braun, and K.G. Knauss, Measurements of pressure effects on n-hexadecane cracking rates, American Chemical Society Preprints, 37 (1614-1620), 1992.

Knauss, K.G., and S.A. Copenhaver, The effect of malonate on the dissolution kinetics of albite, quartz, and microcline as a function of $\mathrm{pH}$ at $70^{\circ} \mathrm{C}$, Applied Geochemistry, 10, 17-33, 1995 a.

Knauss, K.G., and S.A. Copenhaver, The solubility of p-xylene in water as a function of temperature and pressure and derived thermodynamic properties, Geochimica et Cosmochimica Acta, 59 (6), 1995b.

Knauss, K.G., S.A. Copenhaver, R.L. Braun, and A.K. Burnham, Hydrous pyrolysis of the New Albany and Phosphoria Shales: effects of temperature and pressure on the kinetics of production of carboxylic acids and light hydrocarbons, American Chemical Society Preprints, 37, 1621-1627, 1992.

Newmark, R.L., Dynamic Underground Stripping Demonstration Project, Interim Engineering Report, Lawrence Livermore National Laboratory, Livermore, CA, 1992. 


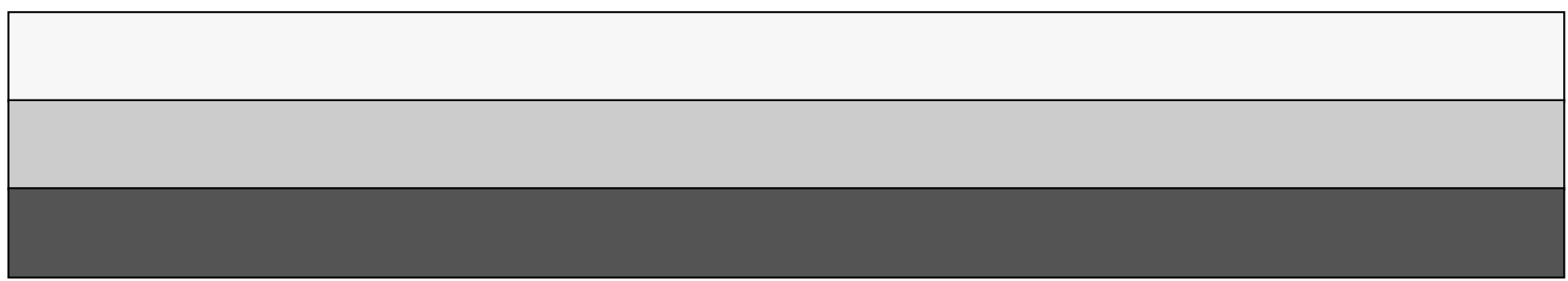

